\title{
Changes in the stability and biomechanics of P22 bacteriophage capsid during maturation
}

\author{
Authors: Ravi Kant, Aida Liauro, Vamseedhar Rayaprolu, \\ Shefah Qazi, Pedro J. de Pablo, Trevor Douglas, \& Brian \\ Bothner
}

NOTICE: this is the author's version of a work that was accepted for publication in Biochimica et Biophysica Acta. Changes resulting from the publishing process, such as peer review, editing, corrections, structural formatting, and other quality control mechanisms may not be reflected in this document. Changes may have been made to this work since it was submitted for publication. A definitive version was subsequently published in Biochimica et Biophysica Acta, vol. 1862, issue 6, DOl\#10.1016/i.bbagen.2018.03.006.

Kant, Ravi, Aida Llauro, Vamseedhar Rayaprolu, Shefah Qazi, Pedro J. de Pablo, Trevor Douglas, and Brian Bothner. "Changes in the stability and biomechanics of P22 bacteriophage capsid during maturation." BBA - Biochimica et Biophysica Acta 1862, no. 6 (June 2018): 1492-1504. DOI:10.1016/j.bbagen.2018.03.006.

Made available through Montana State University's $\underline{\text { ScholarWorks }}$ scholarworks. montana.edu 


\title{
Changes in the stability and biomechanics of P22 bacteriophage capsid during maturation
}

\author{
Ravi Kant ${ }^{\mathrm{a}}$, Aida Llauró ${ }^{\mathrm{b}}$, Vamseedhar Rayaprolu ${ }^{\mathrm{d}}$, Shefah Qazi ${ }^{\mathrm{c}, \mathrm{d}}$, Pedro J. de Pablo ${ }^{\mathrm{b}}$, \\ Trevor Douglas ${ }^{\mathrm{c}}$, Brian Bothner, ${ }^{\mathrm{a}, *}$ \\ a Department of Chemistry and Biochemistry, Montana State University, Bozeman, MT 59717, United States \\ ${ }^{b}$ Departamento de Fisica de la Materia Condensada and Solid Condensed Matter Institute IFIMAC, UAM, Francisco Tomás y Valiente 7, 28049 Madrid, Spain \\ ${ }^{c}$ Department of Chemistry, Indiana University Bloomington, IN 47405, United States \\ d Department of Cell Biology and Neuroscience, Montana State University, Bozeman, MT 59717, United States
}

\begin{abstract}
A B S T R A C T
The capsid of P22 bacteriophage undergoes a series of structural transitions during maturation that guide it from spherical to icosahedral morphology. The transitions include the release of scaffold proteins and capsid expansion. Although P22 maturation has been investigated for decades, a unified model that incorporates thermodynamic and biophysical analyses is not available. A general and specific model of icosahedral capsid maturation is of significant interest to theoreticians searching for fundamental principles as well as virologists and material scientists seeking to alter maturation to their advantage. To address this challenge, we have combined the results from orthogonal biophysical techniques including differential scanning fluorimetry, atomic force microscopy, circular dichroism, and hydrogen-deuterium exchange mass spectrometry. By integrating these results from single particle and population measurements, an energy landscape of P22 maturation from procapsid through expanded shell to wiffle ball emerged, highlighting the role of metastable structures and the thermodynamics guiding maturation. The propagation of weak quaternary interactions across symmetric elements of the capsid is a key component for stability in P22. A surprising finding is that the progression to wiffle ball, which lacks pentamers, shows that chemical and thermal stability can be uncoupled from mechanical rigidity, elegantly demonstrating the complexity inherent in capsid protein interactions and the emergent properties that can arise from icosahedral symmetry. On a broader scale, this work demonstrates the power of applying orthogonal biophysical techniques to elucidate assembly mechanisms for supramolecular complexes and provides a framework within which other viral systems can be compared.
\end{abstract}

\section{Introduction}

Supramolecular-protein complexes carry out many important biological processes. These complexes require assembly, the directions for which are programmed into the amino acid sequence and coordinated via allosteric interactions. Icosahedral virus capsids are excellent systems for studying the process of assembly. In viruses, assembly of a symmetric capsid is orchestrated through a balance of polar and nonpolar interactions of asymmetric subunits [1-3]. Assembly can often be divided into two steps, the first being subunit association, followed by an adoption of the active quaternary structure. The second step can involve covalent interactions and/or conformational changes [4-7]. In step two, subunit reorganization associated with capsid maturation from spherical to quasi-equivalent icosahedral symmetry can be classified into global and local rearrangements. Large global reorganizations are for the most part irreversible and often involve the crossing of a significant energy barrier on the conformational landscape. This is initiated by a specific stimulus, such as, genome packaging, receptor binding, or $\mathrm{pH}$ [4,8-10]. Local reorganizations are transient, resulting from the sampling of different conformations, and have been referred to as capsid breathing [11-13]. Beyond the obvious reasons for understanding viruses, there is increasing interest in the use of protein-based nano-compartments in the field of applied nanotechnology [14-18]. These compartments are assembled from multiple subunits and this self-assembly property can be exploited to incorporate different active molecules inside it. Viruses are pertinent examples of precise, self-assembling, and highly stable nanoparticles. Knowledge and understanding of a virus and its assembly and disassembly mechanisms can be helpful to engineer a nanoparticle for a variety of bioinspired applications [17-23]. The relationship between the assembly and disassembly pathways depends on interaction between inter-protein subunits which further regulates the global stability and integrity of the capsid [24]. 


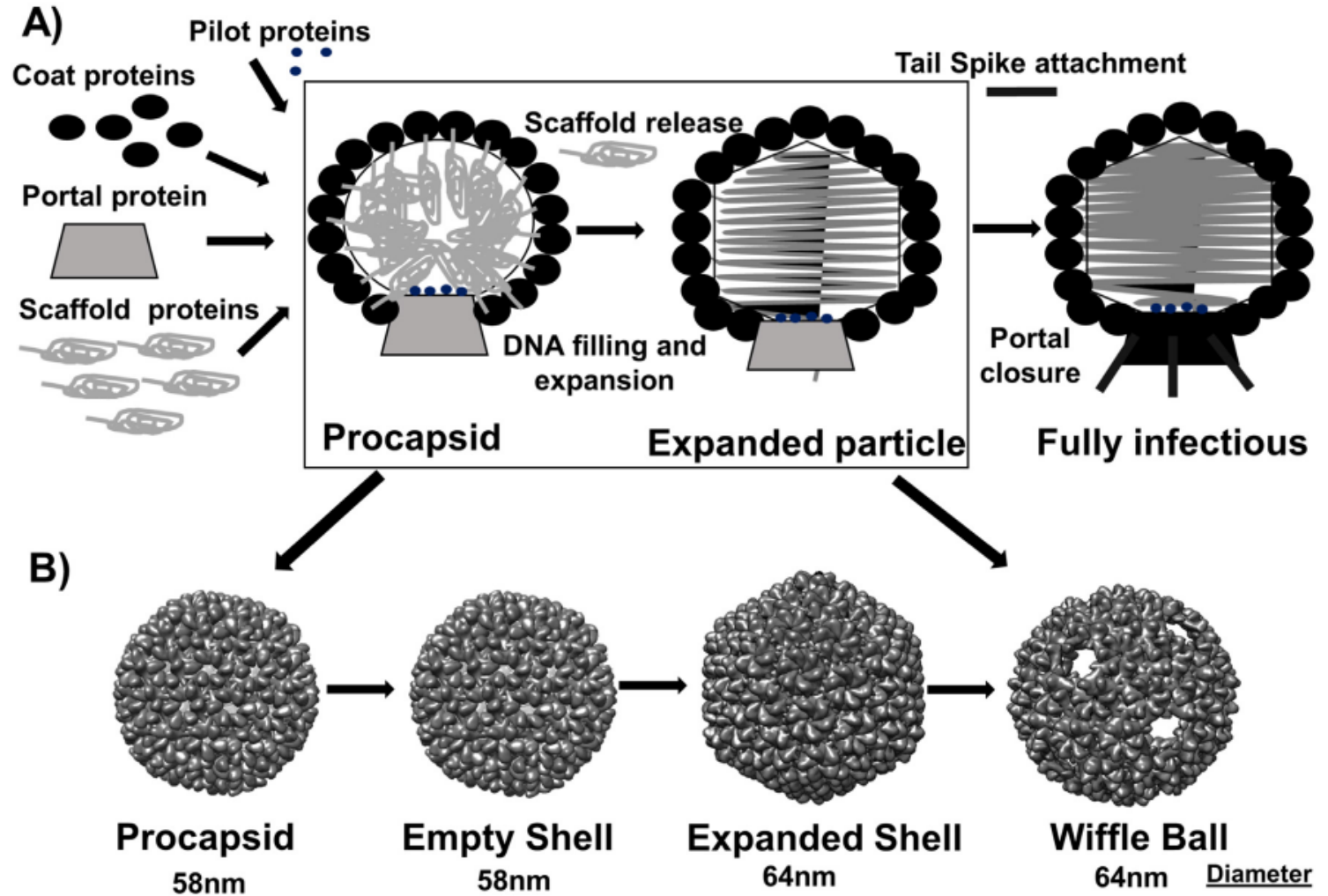

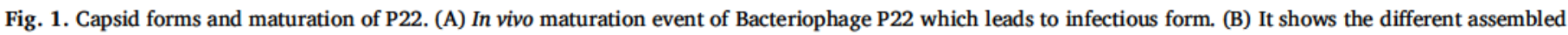

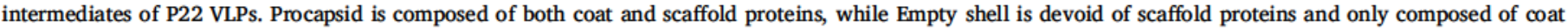

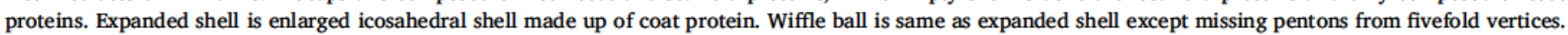
(PDB ID 3iyi-Procapsid, 2xyz-Expanded shell, Wiffle ball-3iyh).

Among icosahedral viruses, P22 is a well-studied model of assembly and maturation. The capsid has $T=7$ icosahedral symmetry. During assembly of the capsid and packaging of the genome, P22 undergoes a series of structural transformations during which a spherical procapsid adopts icosahedral symmetry (Fig. 1). This process of maturation results in a $10 \%$ increase in diameter [25-27]. To assemble P22, 420 molecules of coat proteins interact and co-polymerize with 60-300 molecules of scaffold protein, 12 portal proteins, and 3 ejection proteins to form a metastable procapsid [28-31]. Scaffold proteins are important both in initiating assembly, and during polymerization, where they maintain fidelity and active assembly [31]. The packaging of DNA is an ATPdependent process involving a terminase. During packaging, release of electrostatically bound internal scaffold proteins is followed by a readjustment of the protein lattice and expansion of the capsid. Expansion results in the formation of non-identical, quasi-equivalent contacts between subunits. Quasi-equivalence demands a conformational switching that involves the formation of hexamers and pentamers from the same coat proteins [32]. Thus, small differences in subunit interactions and conformations must occur during P22 maturation. All of these changes are known to influence the free energy status of the expanded form [26,33], but a connection between the biophysical transformation and thermodynamics remains elusive.

The maturation process of P22 can be mimicked in vitro by applying thermal or chemical stress. Heterologous expression of the coat and scaffold protein results in self-assembly of the spherical procapsid (PC) with a diameter of $58 \mathrm{~nm}$. Heat or denaturants will trigger expansion [26,28,34]. Heating of $\mathrm{P} 22$ procapsid at $\mathrm{pH} 7.6$ mimics shell transformations that are part of maturation (Fig. 1) [26]. Incubation of PC in $0.5 \mathrm{M}$ guanidine hydrochloride (GdmHCl) releases scaffold protein, producing an empty shell (ES) [35]. Heating of ES at $65^{\circ} \mathrm{C}$ for $20 \mathrm{~min}$ irreversibly induces an expanded shell (EX) with a diameter of $64 \mathrm{~nm}$ [36-38]. Heating of ES at $75^{\circ} \mathrm{C}$ for $20 \mathrm{~min}$ causes the release of pentons from fivefold axes producing the wiffle ball (WB) form $[37,39]$. Due to the ease of expression and the ability to control maturation in-vitro, P22 has been established as a platform for nanobiotechnology $[16,18,22,40,41]$. The first three morphologies are structural intermediates that are pertinent to the biology of P22 [37]. EX and WB are currently being used as nano-protein containers for a wide variety of cargos [42]. Change in $\mathrm{pH}$ is the natural trigger for initiating maturation in a variety of viruses, including Cowpea chlorotic mottle viruses (CCMV) [43] and Nudaurelia $\omega$ capensis [4]. Therefore, from a nano-biotechnology perspective it is important to understand the effect of $\mathrm{pH}$ on structural intermediates.

HK97 is a relevant model for capsid maturation. P22 and HK97 are both bacteriophages and have a common subunit structure with high $\alpha$ helix content designated as the HK97 fold [44-46]. A comparative study of structural intermediates of HK97 by atomic force microscopy (AFM) showed an increase in Young's modulus and mechanical strength after maturation [7]. The P22 maturation mechanism is different from HK97 in that P22 does not form covalent cross-links, a unique feature of HK97. Therefore, a comparison of these two capsids presents a unique opportunity to investigate biophysical differences between covalent and noncovalent protein complexes. Although numerous studies describe the global rearrangements associated with P22 maturation $[47,48]$, biophysical analyses are limited.

Biophysical and mechanical properties of proteins and protein complexes can be investigated by differential scanning fluorescence (DSF), circular dichroism (CD), atomic force microscopy (AFM) and hydrogen deuterium exchange mass spectrometry (HDX-MS). DSF is an established technique for following the thermal transitions of protein complexes and viruses [49,50]. AFM can be used to image and make measurements of deformation by mechanical force. It has been applied to viruses such as HK97, PBCV, MVM and CCMV etc [51,52]. HDX-MS is sensitive to changes in protein conformation and solvent exposure, demonstrating great utility in the study of smaller and bigger protein 
complexes $[6,53,54]$. In the study presented here, we investigate the biophysical mechanism behind P22 maturation across the four morphologies (PC, ES, EX and WB). During maturation, when the capsid accumulates genetic material, it undergoes a biophysical transformation. Therefore, mature capsids need to find a way to accommodate the change attributed to the presence of genetic material (increase in size and pressure [54]) while maintaining structural integrity. In the field of physical virology, different studies have supported the concept of coat protein-genome interactions [42,55,56] or inter-coat proteins crosslinking for stabilizing a mature capsid [7].

By applying orthogonal techniques, we show that in P22, maturation can be driven by tuning the weak quaternary interactions between subunits, which results in a mature expanded capsid having $T=7$ quasi-equivalent symmetry. As a result of this transformation, mature P22 capsids are relatively rigid assemblies with a stabilized hydrophobic protein core and an enhanced global hydrogen bonding network. We present a free energy model in which expansion is driven by both enthalpic and entropic factors. This is in contrast with the model of HK97 maturation, where rigidity is primarily established by covalent crosslinking [7]. Our findings support a two-stage assembly in P22 maturation. In the first stage, assembly involves the formation of a weaker structure (procapsid) with identical coat protein environment. In the second step, the capsid expands resulting in a mature and stable capsid with quasi-equivalence. These biophysical transformations also result in an increased resistance to stresses such as heat and protein denaturants. From the perspective of nanobiotechnology, we show that just by altering the protein-protein interactions (PC/ES to $\mathrm{EX}$ ) or removing coat proteins interactions at fivefold axis (EX to WB), assembly with altered biophysical and biomechanical properties is produced. The orthogonal techniques presented here thus have broad implications in the field of virus biology and nano-biotechnology.

\section{Materials and methods}

\subsection{Protein purification of $W T P 22$}

P22 WT procapsid made up of 420 subunits, was produced by a heterologous expression system in E. coli. BL21 (DE) E. coli was grown in $1 \mathrm{~L}$ cultures inoculated with $1 \mathrm{~mL}$ starter culture $\left(37^{\circ} \mathrm{C}, 220 \mathrm{rpm}\right)$. After $2 \mathrm{~h}$ $\left(\mathrm{OD}_{600}=0.6\right)$, the cultures were induced with $1 \mathrm{mM}$ IPTG and grown for 4 more hours. Cells were harvested by centrifugation at $3700 \mathrm{~g}$ for $20 \mathrm{~min}$. The cells were resuspended in PBS pH 7.6 and were incubated with DNase, RNase, and lysozyme (all Sigma-Aldrich) for $30 \mathrm{~min}$ at room temperature. Cells were lysed further by sonication on ice (Branson Sonifier 250, Danbury, CT, power 4 , duty cycle $50 \%, 3 \times 5 \mathrm{~min}$ with $3 \mathrm{~min}$ intervals). Bacterial cell debris was removed via centrifugation at $12000 \mathrm{~g}$ for $45 \mathrm{~min}$. The supernatant was then loaded on a $35 \%$ sucrose cushion and centrifuged at $48,000 \mathrm{rpm}$ for $50 \mathrm{~min}$ in an ultra-centrifuge (50.2Ti ultra centrifuge rotor). The resulting virus pellet was resuspended in PBS, pH7.0 and dialyzed to remove sucrose. The P22 ES was prepared by repeated extraction of the scaffolding protein with $0.5 \mathrm{M}$ guanidine- $\mathrm{HCl}$. Purified ES were heated at $65^{\circ} \mathrm{C}$ for $20 \mathrm{~min}$ to obtain P22 expanded and at $75^{\circ} \mathrm{C}$ for $20 \mathrm{~min}$ to obtain P22 wiffleball. Each individual capsid form was routinely characterized using SDS-PAGE, native agarose gels, transmission electron microscopy (TEM, Leo $912 \mathrm{AB}$ ), and dynamic light scattering (DLS, Brookhaven 90Plus, Brookhaven, NY). The protein concentration was determined by absorbance at $280 \mathrm{~nm}$ using the extinction coefficient $\left(44,920 \mathrm{M}^{-1} \mathrm{~cm}^{-1}\right)$.

\subsection{Differential scanning fluorescence (DSF)}

Differential scanning fluorescence scans of P22 morphologies (PC, ES, EX and WB) were performed in citrate phosphate buffer $\mathrm{pH} 7$ (prepared from stock, $100 \mathrm{mM}$ citric acid and $200 \mathrm{mM}$ disodium hydrogen phosphate). P22 samples were diluted in citrate phosphate buffer with $50 \mathrm{mM} \mathrm{NaCl}$ concentration to obtain the final virus concentration $(0.15 \mathrm{mg} / \mathrm{ml})$. To each sample, $2.5 \mu \mathrm{L}$ of $1 \%$ SyproOrange dye (Invitrogen 140 Inc. S6651) was added to obtain the final reaction volume to $25 \mu \mathrm{L}$. The assays were conducted in a qPCR instrument (Corbett Research, RG-3000) with temperature elevating from 25 to $99^{\circ} \mathrm{C}$, increasing 0.5 degrees every $30 \mathrm{~s}$. Lysozyme was run as positive control at final concentration of $0.3 \mathrm{mg} / \mathrm{ml}$. DSF assays were also performed in different $\mathrm{pH}(2.6,4,5,6,8$, and 9) citrate phosphate buffer with the same experimental set up. Melting temperature of samples was determined by calculating the first derivative $(\mathrm{dF} / \mathrm{dT})$ from raw fluorescence data. For partial convoluted peaks, tip of the peak is used to calculate the melting temperature. Thermal denaturation of P22 samples were also studied in the presence of fixed concentration of guanidine-hydrochloride concentration $(0.5,1,2,3 \mathrm{M})$ at neutral $\mathrm{pH}$. The reaction conditions and experimental set up in this experiment were same as for different $\mathrm{pH}$ DSF assays.

\subsection{Circular dichroic spectroscopy}

Circular dichroic (CD) spectra were recorded on JASCO-815 spectrometer. CD measurements were performed on PC, ES, EX and WB samples placed in fused silica cuvette with pathlength $10 \mathrm{~mm}$ (Starna Cells, Atascadero, CA). Tight fitting stopper was placed on sample filled silica cuvette to prevent sample evaporation. CD spectra were performed between $25^{\circ} \mathrm{C}$ and $95^{\circ} \mathrm{C}$ with the ramping rate of $1{ }^{\circ} \mathrm{C} / \mathrm{min}$ controlled by a JASCO programmable Peltier-cooled temperature controller. Final concentration of samples was maintained at $0.03 \mathrm{mg} / \mathrm{ml}$. For thermal dependent scan, the parameters were set in measure range $190-300 \mathrm{~nm}$, scan speed of $100 \mathrm{~nm} / \mathrm{min}$, with a $1 \mathrm{~nm}$ bandwidth and $1 \mathrm{~nm}$ data pitch. The UV data was recorded at every $5{ }^{\circ} \mathrm{C}$ and the dichroic activity was supervised unceasingly and each observed spectrum was an average of 3 scans.

\subsection{AFM experiments}

Measurements were performed with an AFM microscope (Nanotec Electrónica S.L., Madrid, Spain) operating in Jumping mode plus [57]. Rectangular silicon-nitride cantilevers (Olympus, RC800PSA) with a nominal spring constant of $0.05 \mathrm{~N} / \mathrm{m}$ were used and calibrated using Sader's method [58]. Maximum imaging force during the measurement was $100 \mathrm{pN}$. The experiments were carried out under physiological conditions. One $20 \mu \mathrm{l}$ drop of diluted stock solution was incubated on a silanized glass surface [59] and, after $30 \mathrm{~min}$, washed with buffer until a volume of $60 \mu \mathrm{l}$ was reached. The tip was also pre-wetted with a $30 \mu \mathrm{l}$ drop of buffer.

All AFM images were processed using WSxM software [60]. Capsids stiffness and breaking force was determined as described in [61]. Viral particles were considered as thin-shells that presented a linear elastic response upon deformation with the AFM tip. The elastic constant (stiffness) of the particle was obtained from the slope of the initial linear part of the force-indentation curve. The breaking force was defined as the maximum force reached during the deformation of the particle, prior to the breakage of the shell. The critical strain was defined as the ratio between the maximum indentation that the particle withstands (corresponding to the deformation at the breaking force) and the height of the particle (i.e., $\varepsilon_{\text {critical }}=\frac{\delta_{\text {critical }}}{\text { height }}$, where is the critical indentation).

\subsection{Hydrogen deuterium exchange mass spectrometry (HDX-MS)}

Conformational flexibility of P22 samples were studied by intact protein hydrogen deuterium exchange mass spectrometry. This experiment was carried out on purified PC, ES, EX and WB capsids separately. Exchange reaction was instigated by 10 fold dilution of P22

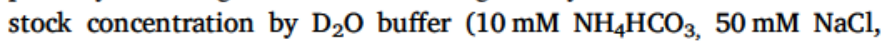
$\mathrm{pH}$ 7.4). Final concentration of all samples after dilution was $0.1 \mathrm{mg} /$ 
ml. Hydrogen deuterium experiments were performed on 1290 UPLC series coupled to micro-TOF spectrometer (Bruker Daltonics) operated in positive electrospray ionization mode. Auto sampler was set to draw samples from the vial at different time points $(0.5,2.5,5.5$. 12.5, 37.5, $60.5,90.5,720 \mathrm{~min})$. For Quenching of reaction, HxSil C8 reversed phase Hamilton column $(20 \times 2.3 \mathrm{~mm})$, frit porosity $2 \mu \mathrm{m}$ is pre-equilibrated with acid quenching conditions $[20 \%(\mathrm{v} / \mathrm{v})$ acetonitrile, $80 \%$ $\mathrm{H}_{2} \mathrm{O}$ and $0.1 \%$ formic acid ( $\mathrm{w} / \mathrm{v}$ ), $\mathrm{pH} 2.4$ ]. The gradient conditions were set as follows: $0.5 \mathrm{~min}, 40 \% \mathrm{~B}$; 0.5-0.7 $\mathrm{min}, 40-95 \% \mathrm{~B}$; $1.3 \mathrm{~min}, 95 \% \mathrm{~B}$, $1.5 \mathrm{~min} 20 \%$ where solvent A: $0.1 \%$ formic acid in water and solvent $\mathrm{B}$ : $0.1 \%$ FA in acetonitrile. The flow rate was $0.5 \mathrm{ml} / \mathrm{min}$, auto sampler and column compartment temperature were set at temperature $25^{\circ} \mathrm{C}$ and $37^{\circ} \mathrm{C}$. Data processing and analysis was performed with the help of Bruker Data Analysis package version 4.0. The maximum entropy deconvolution algorithm was used to calculate the increase in the mass of the P22 sample at different time points in the spectral range of $800 \mathrm{~m} / \mathrm{z}$ to $1600 \mathrm{~m} / z$, which covers the majority of subunit charge envelope. Mass of deuterated samples at different points is calculated and the mass of control sample is subtracted from them to determine the total exchanged deuteriums. The relative mass difference between deuterated and undeuterated samples were calculated and plotted against time.

\subsection{Calculation of solvent excluded surface area}

The cryo-EM structures of P22 were not solved at atomic resolution $[49,62]$ and could not provide the positions of the side chains. Sidechains were necessary to compute the solvent excluded surface areas of subunits. To address this issue, $\mathrm{C} \alpha$ chains from the cryo-EM structures (2xyy, 2xyz, 3iyi, 3iyh) were extracted and were submitted to the Phyre2 server [63] for a template based side chain structure modeling. In brief, the P22 amino acid sequence was submitted to the Phyre2 server [63] along with $\mathrm{C} \alpha$ chain extracted from the cryo-EM structure. The $C \alpha$ chain was used as the template to make sure the output model structurally aligns well with the cryo-EM. During this process, the sidechains were also predicted and included in the output model. Parent et al... solved the structures 3iyi and 3iyh whereas Chen et al solved the structures 2xyy and 2xyz. In the case of 3iyi and 3iyh, the C $\alpha$ structures were missing a number of residues ( $\sim 40$ amino acids). This discrepancy was accounted for during sidechain modeling by submitting only the sequence seen in the structure. To account for quasi-symmetry and for conformational polymorphism, $\mathrm{C} \alpha$ chains from multiple subunits were submitted to the Phyre2 server. For each of the structures obtained from Phyre2, clashes were eliminated and refinement was done using ModRefiner [64]. The refined models were then structurally aligned into their respective quasi and icosahedral positions in the P22 capsid using the cryo-EM structure as the guide. Solvent excluded surface area (SESA) was computed from these aligned models with a probe radius of $\sim 1.4 \AA$ for each subunit using UCSF Chimera software [65]. The structure alignment was done using the matchmaker tool in UCSF Chimera software and SESA calculations were also performed in the same software. A guide cage was created to correctly position the modeled protein subunits on their respective icosahedral axes. As the procapsid has a more spherical structure, the sphere factor of the guide cage ( $29 \mathrm{~nm}$ radius) created was set to maximum. Similarly, sphere factor for the expanded shell and the wiffle ball guide structures ( $34 \mathrm{~nm}$ radius) was set to the minimum to show the icosahedral nature of the actual capsid (Fig. 2.7 A, B). Each corresponding subunit in all the forms is colored the same. The numeric values for specific interactions are listed in the table in the supplemental material (Table S1).

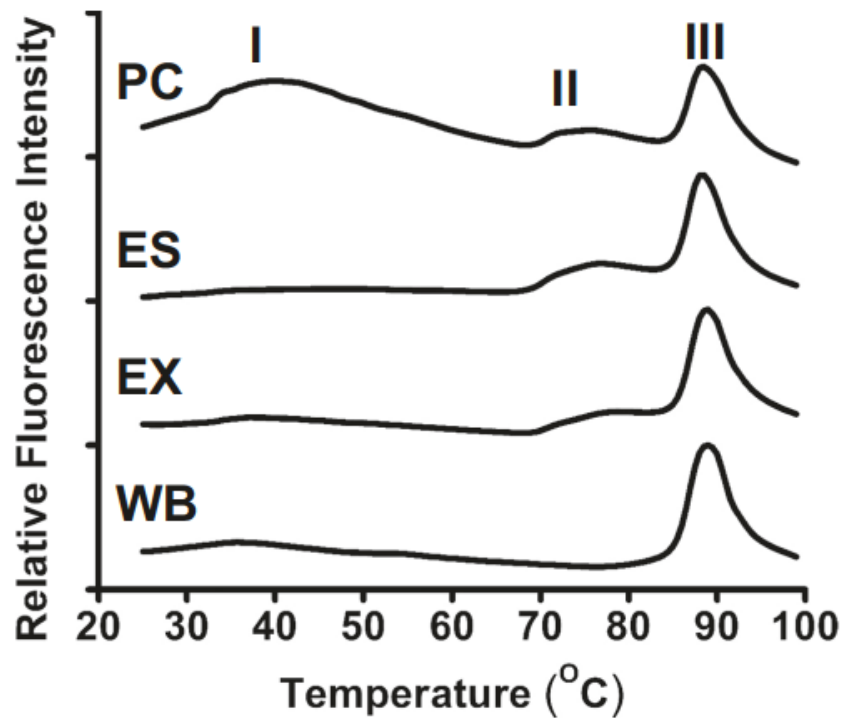

Fig. 2. DSF analysis of P22 capsids. PC, ES, EX and WB were heated from 25 to $99^{\circ} \mathrm{C}(\mathrm{pH} 7.0)$ while monitoring fluorescence intensity of Sypro Orange. Thermal scan of PC (top) shows the presence of three transitions (I, II, III) which correspond to different stages of maturation (as shown in Fig. 1). ES, which has lost scaffold proteins shows only two transitions (II, III). EX also shows two transitions (II, III), while WB, which is devoid of pentamers has only one transition (III).

\section{Results and discussion}

\subsection{Differential scanning ftuorescence reveals heat triggered structural transitions}

P22 maturation involves a significant expansion of the capsid driven by subunit rearrangement [62]. This prompted us to test if changes in particle stability were associated with the transitions. In order to measure the thermal stability of P22 bacteriophage pre and post expansion, DSF was used. DSF is a high throughput, straightforward, and sensitive technique for tracking thermal unfolding transitions of proteins. It uses a fluorescent dye that is quenched in an aqueous environment. An increase in fluorescence intensity is observed upon interaction with buried hydrophobic regions of a protein $[66,67]$. This technique is useful for studying thermal transitions and measuring the thermal stability of viruses and virus-like particles [50]. DSF thermal scans of PC, ES, EX and WB were performed from 25 to $99^{\circ} \mathrm{C}$ at pH 7.0. The scan of PC, which contains both coat and scaffold proteins, exhibited three transitions labeled I, II, III at $43.5^{\circ} \mathrm{C}, 75^{\circ} \mathrm{C}$, and $88.5^{\circ} \mathrm{C}$, respectively (Fig. 2, Table 1). Heating of ES, which no longer contains scaffold protein, had two thermal transitions that matched II and III from PC. The EX form of capsid also displayed two transitions, again matching II and III. WB, which is missing the pentamers, showed a single transition at the same temperature as III.

A comparison of DSF scans of PC and ES revealed the absence of transition I in the ES (Fig. 2). The major difference between PC and ES is the absence of scaffold, strongly suggesting that transition I is associated with scaffold release. Galisteo and King demonstrated that there is no distinct thermal transition during unfolding of scaffold proteins possibly due to a general lack of tertiary structure [26]. Transition I was broad and occurred at relatively low temperature $\left(30^{\circ} \mathrm{C}\right.$ to $\left.50^{\circ} \mathrm{C}\right)$, which further supports our interpretation. A comparison of thermal profiles from PC, ES, EX and WB revealed the absence of transition II in 
Table 1

Transition temperature from DSF analysis of P22 morphologies at different pHs.

\begin{tabular}{|c|c|c|c|c|c|c|c|c|c|}
\hline P22 samples & Temp range $\left({ }^{\circ} \mathrm{C}\right)$ & Transitions & pH 2.5 & pH 4 & pH 5 & pH 6 & $\mathrm{pH} 7$ & pH 8 & $\mathrm{pH} 9$ \\
\hline \multirow[t]{3}{*}{ PC } & $30-45$ & I & $37.0 \pm 0.5^{\mathrm{a}}$ & $38.0 \pm 0.5$ & $42.0 \pm 16$ & $43.5 \pm 16$ & $43.5 \pm 16$ & $43.5 \pm 16$ & $43.5 \pm 16$ \\
\hline & $70-80$ & II & $37.0 \pm 0.5^{\mathrm{a}}$ & $72.0 \pm 0.16$ & $75.0 \pm 0.16$ & $75.0 \pm 0.16$ & $75.0 \pm 0.16$ & $75.0 \pm 0.16$ & $75.0 \pm 0.16$ \\
\hline & $80-90$ & III & $62.5 \pm 0.1$ & $84.5 \pm 0.5$ & $88.5 \pm 0.5$ & $88.5 \pm 0.5$ & $88.5 \pm 0.5$ & $88.5 \pm 0.5$ & $88.5 \pm 0.5$ \\
\hline \multirow[t]{2}{*}{ ES } & $70-80$ & II & $39.0 \pm 0.5$ & $75.0 \pm 0.16$ & $75.0 \pm 0.16$ & $75.0 \pm 0.16$ & $75.0 \pm 0.16$ & $75.0 \pm 0.16$ & $75.0 \pm 0.16$ \\
\hline & $80-90$ & III & $63.5 \pm 0.1$ & $88.5 \pm 0.5$ & $88.5 \pm 0.5$ & $88.5 \pm 0.5$ & $88.5 \pm 0.5$ & $88.5 \pm 0.5$ & $88.5 \pm 0.5$ \\
\hline \multirow[t]{2}{*}{ EX } & $70-80$ & II & $39.5 \pm 0.5$ & $75.0 \pm 0.16$ & $75.0 \pm 0.16$ & $75.0 \pm 0.16$ & $75.0 \pm 0.16$ & $75.0 \pm 0.16$ & $88.5 \pm 0.5$ \\
\hline & $80-90$ & III & $64.5 \pm 0.1$ & $88.5 \pm 0.5$ & $88.5 \pm 0.5$ & $88.5 \pm 0.5$ & $88.5 \pm 0.5$ & $88.5 \pm 0.5$ & $88.5 \pm 0.5$ \\
\hline WB & $80-90$ & III & $64.5 \pm 0.1$ & $88.5 \pm 0.5$ & $88.5 \pm 0.5$ & $88.5 \pm 0.5$ & $88.5 \pm 0.5$ & $88.5 \pm 0.5$ & $88.5 \pm 0.5$ \\
\hline
\end{tabular}

a $\mathrm{Tm}$ of transition I and II is same for procapsid at pH 2.6 as these events are convoluted.

WB. WB is structurally similar to EX, as both have icosahedral symmetry and a diameter of $64 \mathrm{~nm}$. The difference is the absence of pentamers in WB. Together, this data strongly advocates that transition II is the release of pentamers. However, transition II is relatively broad, suggesting a non-cooperative process. Therefore, release of pentamers would occur independently at each of the 125 -fold vertices.

Previous experiments using differential scanning calorimetry (DSC) to analyze P22 maturation observed three endothermic transitions [26]. The temperature of these transitions $\left(48.5^{\circ} \mathrm{C}, 71.4^{\circ} \mathrm{C}\right.$ and $87.3^{\circ} \mathrm{C}$ ) correspond with what we have observed by DSF. Apart from the above three transitions, a single exothermic transition was also observed by DSC at $61^{\circ} \mathrm{C}$. Electron microscopy, size exclusion chromatography and agarose gel electrophoresis also confirmed the release of scaffold at $48.5^{\circ} \mathrm{C}$ and expansion of procapsid at $61^{\circ} \mathrm{C}$. Complete denaturation of particles was reported at $85^{\circ} \mathrm{C}$ [26]. This data is consistent with our DSF experiments. However, only three transitions were observed by DSF compared to the four transitions in DSC. The transition related to expansion was absent, suggesting that once PC has lost scaffold, the hydrophobic core of the capsid has largely been established and refolding involving exposure of hydrophobic regions does not occur. It is only after ES has transitioned through EX and the pentamers are released to form WB that the second DSF transition is observed.

Structural studies indicate that large movements of pentons along the fivefold axes are similar both in in-vivo and in-vitro expansion [68]. Difference maps of in-vivo and in-vitro expanded particles show noteworthy similarity, further validating the use of thermally induced transition to study the maturation of P22 [37]. The release of pentamers is not an in-vivo event, rather it is only observed during heat-induced maturation. This loss of pentons suggests a destabilization of penton and hexon units at higher temperature and a possible mechanism for relieving stress in an icosahedral particle. Continuum elasticity theory predicts that there is high lateral compression in pentamer units and that this stress increases significantly with Triangulation number [69]. Previous work on human adenovirus mechanics has experimentally demonstrated that pentons are under stress [70]. A previous investigation has demonstrated that the penton moves radially outward by $\sim 37 \AA$ upon heating. This movement is followed by the release of pentamers at the icosahedral fivefold axis [68]. In-vivo, the interaction between capsid protein and the DNA genome has been proposed to stabilize the pentons, averting release of pentamers during expansion and DNA packaging [37]. These transitions are independent, and we propose that each form of capsid occupies a local energy minimum. Transition I is associated with the release of scaffold protein, transition II is associated with the release of pentamers at the fivefold axis, and transition III is the final denaturation of expanded capsids.

\subsection{Impact of $p H$ on thermal transitions}

While temperature is a convenient tool for nudging capsids over energy barriers associated with maturation, it is of course not a part of the biological process. A more relevant parameter is $\mathrm{pH}$, which can initiate maturation by altering electrostatic interactions between subunit interfaces. The small icosahedral RNA tetravirus, Nudaurelia $\omega$ capensis $(\mathrm{N} \omega \mathrm{V})$, can be induced to mature from procapsid to capsid by decreasing the $\mathrm{pH}$ from 7.0 to 5.0. The mature capsid form is morphologically distinguishable, and smaller in diameter [4,71]. Another example is cowpea chlorotic mottle virus (CCMV), which at pH 5.0 is found as a closed $28 \mathrm{~nm}$ particle. At $\mathrm{pH} 7.0$ and low ionic strength, CCMV transitions to a swollen fenestrated form with the diameter increasing by $10 \%$ [72]. Inspired by these studies, we were interested in the impact of $\mathrm{pH}$ on heat induced structural transitions in P22. To test this, DSF of each form was repeated at $\mathrm{pH} 2.6,4.0,5.0,6.0,8.0$ and 9.0. DSF results at pH5.0-9.0 showed the same transitions and similar temperatures as those observed at $\mathrm{pH} 7.0$ (Fig. 3). At pH 4.0 PC transition I was lower by $5^{\circ} \mathrm{C}$, transition II by $3{ }^{\circ} \mathrm{C}$, and transition III by $4^{\circ} \mathrm{C}$ (Table 1). No significant changes in $\mathrm{T}_{\mathrm{m}}$ were observed for transitions associated with ES, EX and WB at $\mathrm{pH} 4.0$. This observation for PC suggests that at low $\mathrm{pH}$, the interaction of scaffold and coat protein is disrupted and scaffold protein is released relatively earlier. This early release of scaffold results in partial destabilization of the coat protein interactions in the PC, thereafter all the successive transitions occurred at relatively lower temperature (Fig. 3). P22 particles remain intact at even lower $\mathrm{pH}$, however, DSF scans at $\mathrm{pH} 2.6$ revealed that they were destabilized. The DSF scan of PC at pH 2.6 had only two transitions, the first (I/II) centered at $37^{\circ} \mathrm{C}$ and second transition (III) centered at $62.5^{\circ} \mathrm{C}$. ES and EX had two transitions (II and III) at slightly higher temperatures than in PC (Table 1). As expected, WB showed only the final transition (III) at $65.5^{\circ} \mathrm{C}$, associated with particle disruption. These results show that with the exception of the PC, all forms of P22 capsid remained stable between $\mathrm{pH} 4-9$. Below pH 4, P22 particles showed substantial thermal destabilization. But the relative intensity of transition III increased in the order of $\mathrm{PC}<\mathrm{ES}<\mathrm{EX} / \mathrm{WB}$ suggesting high thermal stability after expansion (Table 1 ). From this, we conclude that from a biological perspective $\mathrm{pH}$ has little effect on P22, however, in use as a nanomaterial, disassembly of cargo bound capsid can be triggered by dropping the $\mathrm{pH}$ to 2.5 . But this low $\mathrm{pH}$ may influence the cargo biophysical characteristics, therefore, pH below 4 should be considered with caution.

\subsection{Maturation increases chemical resistance}

To gain a deeper understanding of the nature of capsid protein interactions during maturation, impact of the chemical denaturant $\mathrm{GdmHCl}$ was investigated. At low concentration, $0.5 \mathrm{M}, \mathrm{GdmHCl}$ is used to release scaffold protein without changing the integrity of capsid [35]. At higher concentrations, GdmHCl alters the free energy of folding, making the folded form less favorable. Studies of model proteins indicate that the ionic nature of $\mathrm{GdmHCl}$ masks electrostatic interactions of proteins leading to unfolding [73-75]. A recent study involving solvent effects on protein unfolding has also reported the destabilizing effect of $\mathrm{GdmHCl}$ on proteins by facilitating the aqueous solvation of non-polar side chains and back bone surface area [76]. Irrespective of the mechanism, $\mathrm{GdmHCl}$ is a commonly used tool for investigating protein denaturation. 

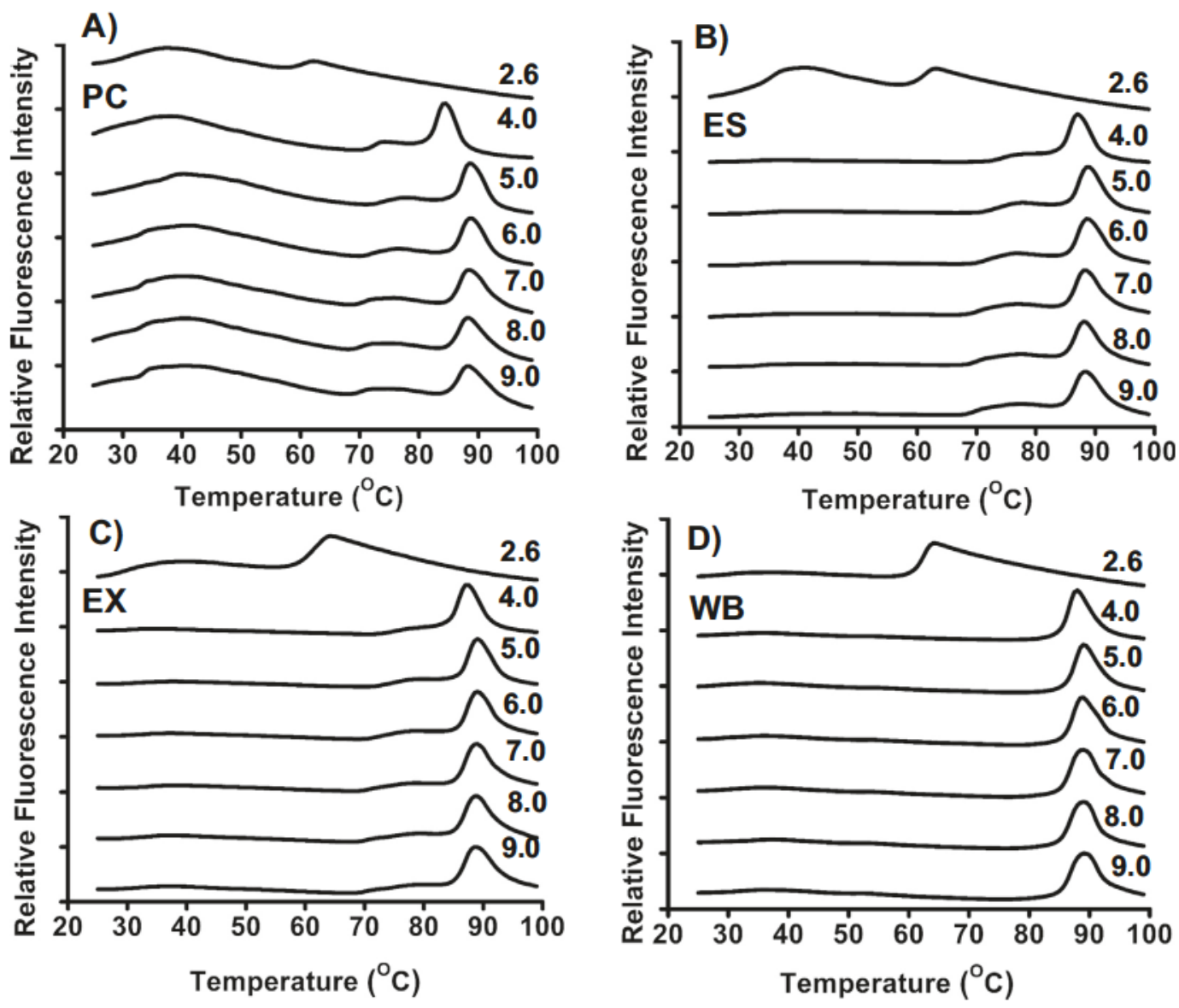

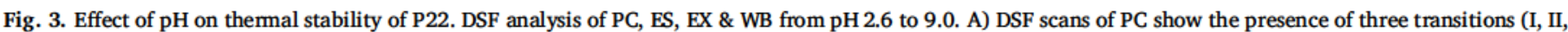

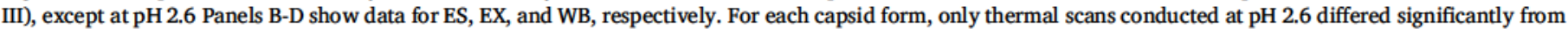

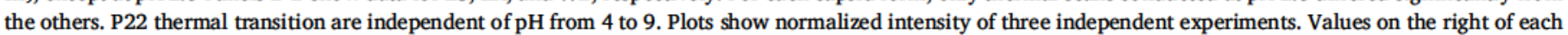
plot indicate $\mathrm{pH}$.

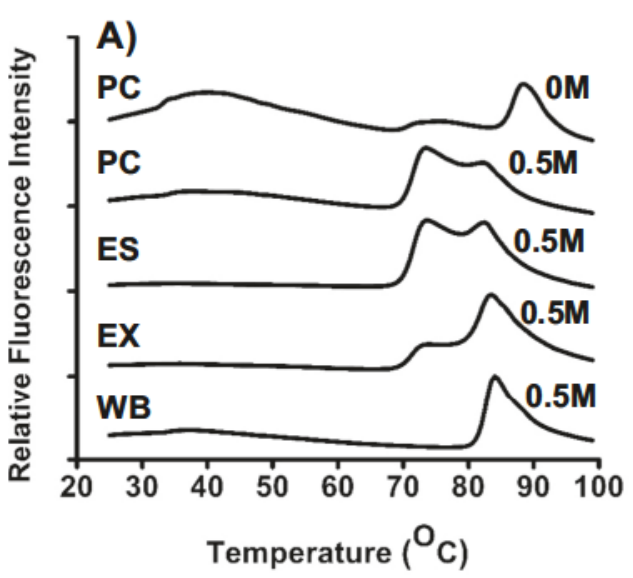

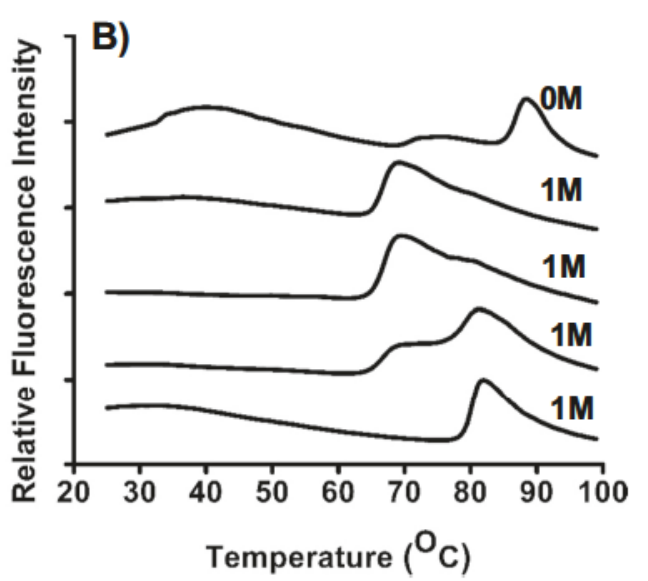

Fig. 4. DSF monitoring of chemical stability of P22. PC, ES, EX \& WB analyses was performed in increasing concentrations of guanidine hydrochloride. A) $0.5 \mathrm{M} \mathrm{Gdm}-\mathrm{HCl}$. B) $1 \mathrm{M} \mathrm{Gdm}-\mathrm{HCl}$. Plots are the nomalized average intensity of three independent experiments. Higher concentrations of Gdm$\mathrm{HCl}$ are show in supplemental material.
DSF thermal scans of PC, ES, EX and WB were performed at different concentrations of $\mathrm{GdmHCl}(0.5,1,2$ and $3 \mathrm{M})$ at $\mathrm{pH} 7.0$. In $0.5 \mathrm{M}$ $\mathrm{GdmHCl}, \mathrm{PC}$ Showed a decrease in intensity of transition I and partial convolution of transitions II and III (Fig. 4A). Compared with untreated particles, temperature of transitions II and III were lowered by $2{ }^{\circ} \mathrm{C}$ and $6^{\circ} \mathrm{C}$ respectively (see Table 2). GdmHCl release of scaffold from procapsid could account for the near absence of transition I. (Fig. 4A). This interpretation is consistent with a previous study where incubation in $0.5 \mathrm{M} \mathrm{GdmHCl}$ was shown to remove scaffold subunits from purified procapsids. The DSF curve of ES revealed a partial convolution of transition II \& III. This partial convolution of transitions II and III suggests they are less distinct energetically. In ES the fluorescence intensity ratio of transitions II:III was nearly $1: 1$, whereas in PC, transition II intensity was higher than transition III (Fig. 4A). The melting temperature of ES transitions II and III were centered at $73^{\circ} \mathrm{C}$ and $82.5^{\circ} \mathrm{C}$ as well as for PC (Table 2). For EX, there is a reduction in the intensity of transition II, this could be due to the release of a small subset of pentons prior to transition.

Heating of $\mathrm{PC}$ at a higher concentration (1 M GdmHCl) resulted in the complete convolution of transitions II and III into a single transition. 
Table 2

Transition temperature from DSF analysis of P22 samples.

\begin{tabular}{lllll}
\hline P22 samples & Transitions & $0.5 \mathrm{M} \mathrm{GdmHCl}$ & $1 \mathrm{M} \mathrm{GdmHCl}$ & 2M GdmHCl \\
\hline PC & I & $34.5 \pm 0.5$ & - & - \\
& II & $73 \pm 0.5$ & - & - \\
& III & $82.5 \pm 0.5$ & $68.5 \pm 0.16$ & $53.5 \pm 0.16$ \\
ES & II & $73 \pm 0.5$ & - & - \\
& III & $82.5 \pm 0.5$ & $69.5 \pm 0.16$ & $56 \pm 0.16$ \\
EX & II & $73 \pm 0.5$ & $70 \pm 0.16$ & $56.5 \pm 0.16$ \\
WB & III & $84 \pm 0.5$ & $81.5 \pm 0.16$ & $77.5 \pm 0.16$ \\
& III & $84 \pm 0.5$ & $82 \pm 0.16$ & $78 \pm 0.16$ \\
\hline
\end{tabular}

This suggests the concomitant release of pentamers and particle denaturation. ES behaves much the same, with the exception of a very small shoulder peak in the latter half of the transition (Fig. 4B), indicating that it maintains a structural transition to a greater extent than a PC. The melting temperature of the convoluted transitions for both PC and ES was centered at $68.5^{\circ} \mathrm{C}$ (Table 2). In contrast to the PC and ES, EX retained transitions II and III distinctly. The melting temperature of the prominent transition III was $84^{\circ} \mathrm{C}$ for both EX and WB. In $1 \mathrm{M} \mathrm{GdmHCl}$ thermal transitions differed by nearly $11^{\circ} \mathrm{C}$ between non-expanded (PC, ES) and expanded particles (EX, WB) for transition III. Heating in $2 \mathrm{M}$ $\mathrm{GdmHCl}$ resulted in significant loss of structural transitions for PC and ES, contrary to EX and WB which retained distinct transitions (Table 2 and Fig. S3A).

Heating in $3 \mathrm{M} \mathrm{GdmHCl}$ showed complete loss of all transitions for each morphology (Fig. S3). The addition of $\mathrm{GdmHCl}$ had a more pronounced destabilization effect on spherical (PC and ES) compared to icosahedral capsids (EX and WB). This data is consistent with study on another Icosahedral T7 capsid where mature capsid exhibited resistance to $\mathrm{GdmHCl}$ mediated global denaturation [77]. In DSF, melting temperature is defined as the temperature at which maximal binding of the hydrophobic dye SYPRO Orange is observed. Therefore, DSF reports on the destabilization of hydrophobic protein regions. Our denaturant study confirms that once the P22 particle matures, the hydrophobic core is stabilized and can better resist denaturant. This observation is supported by Raman spectroscopy of P22, PC and EX which revealed that all six tryptophans in PC readily exchange hydrogens, whereas after conversion to EX exchange decreases [47]. The large increase in $T_{m}$ associated with expansion suggests that the changes in protein stability go beyond the tryptophan residues.

\subsection{Protein subunit refolding does not have a significant role in maturation}

To gain further insight into the structural changes associated with P22 maturation, we turned to Circular Dichroism (CD), which provides information specific to protein secondary structure. It is useful for the study of local or global protein unfolding as a function of temperature or denaturants [78-80]. Spectra of all four P22 morphologies were recorded from 25 to $95^{\circ} \mathrm{C}$. Our $\mathrm{CD}$ data showed that P22 capsid secondary structure is rich in $\beta$ strands. This data is consistent with previous $C D$ data collected on purified coat proteins [33] and structural model [62]. Analysis of the thermal scans showed no significant change
A)

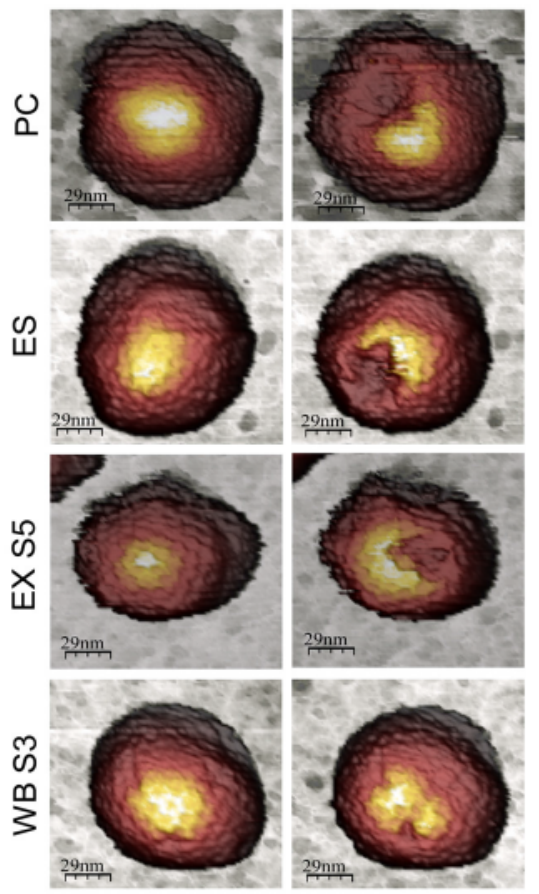

B)

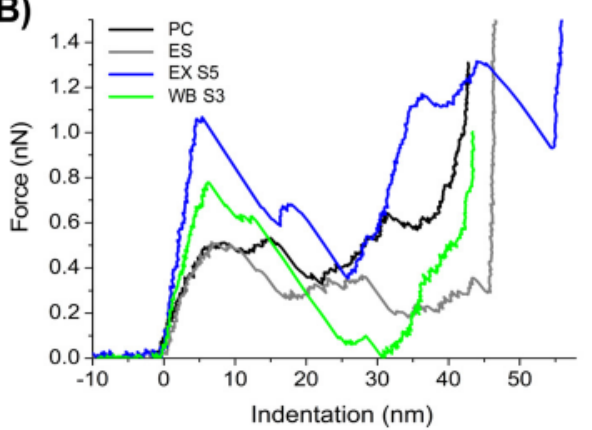

C)

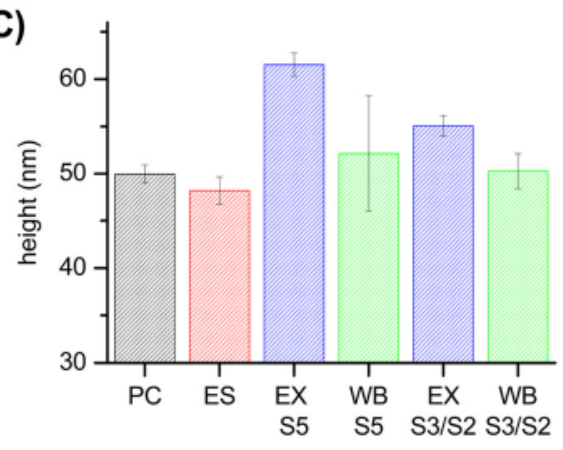

D)

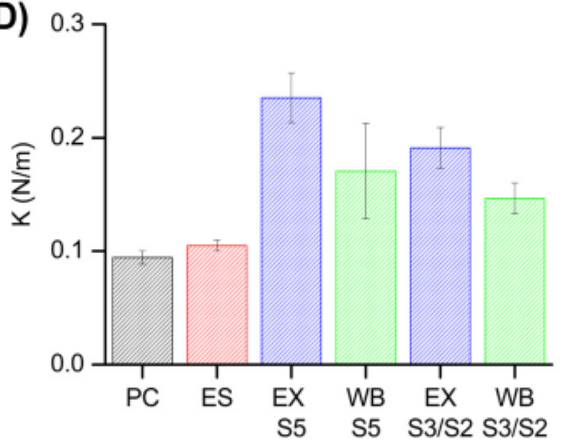

E)

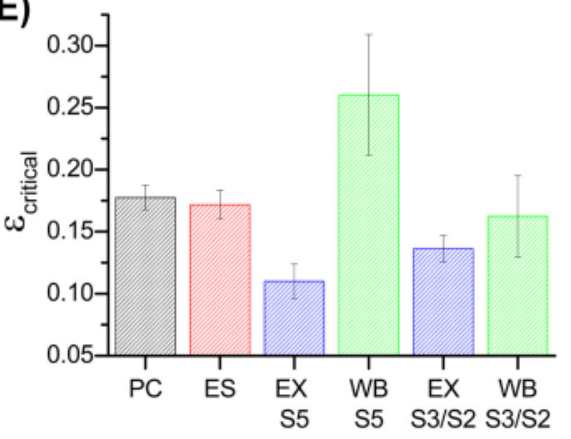

Fig. 5. AFM analysis of P22 morphology. (A) AFM images of individual P22 particles before (left) and after the breakage (right). From top to bottom: procapsid, empty shell (lacking scaffolding protein), expanded capsids (along the 5 -fold symmetry axes) and wiffle ball (along the 3-fold symmetry axes). Color bar, from substrate to the highest point: grey-red-yellow-white. (B) Force-indentation curves corresponding to the particles shown in panel A. (C) Comparison of the height, (D) elastic constant $(\mathrm{k})$, and (E) critical strain ( $\left.\varepsilon_{\text {critical }}\right)$ for the different morphologies (mean \pm SE). For EX and WB the symmetry could be distinguished and particles were classified in two groups (S5 and S3/S2). 
Table 3

AFM measurements of P22 particles.

\begin{tabular}{lllll}
\hline Capsids & \# of particles & $K$ & $\varepsilon_{\text {critical }}$ & Height \\
\hline & & $\mathrm{N} / \mathrm{m}$ & $\mathrm{nm}$ \\
\hline PC & 32 & $0.094 \pm 0,006$ & $0.18 \pm 0.01$ & $50 \pm 1$ \\
ES & 12 & $0.105 \pm 0,005$ & $0.17 \pm 0.01$ & $48 \pm 1$ \\
EX S5 & 8 & $0.22 \pm 0.02$ & $0.12 \pm 0.01$ & $62 \pm 1$ \\
WB S5 & 3 & $0.17 \pm 0.04$ & $0.26 \pm 0.05$ & $52 \pm 6$ \\
EX S3/S2 & 11 & $0.20 \pm 0.02$ & $0.14 \pm 0.02$ & $56 \pm 1$ \\
WB S3/S2 & 9 & $0.13 \pm 0.01$ & $0.16 \pm 0.03$ & $51 \pm 1$ \\
\hline
\end{tabular}

in the secondary structure from 25 to $85^{\circ} \mathrm{C}$ at pH 7.0 (Fig. S1). However, above $85^{\circ} \mathrm{C}$ there was a sharp transition in the CD curves, followed by a complete loss of signal (Fig. S1). The spectra do not transition through a random coil signal, but rather a loss of signal. This suggests that subunit dissociation was followed by rapid aggregation and precipitation. The temperature transitions observed by CD, DSF, and DSC are highly similar [26]. Our CD experiments argue against secondary structural changes as a driving force for the global structural transitions.

\subsection{AFM analysis shows an increase in mechanical rigidity with maturation}

Our data showed that maturation of P22 increases particle stability to heat and denaturant. This led us to ask whether this translates into changes in mechanical properties as well. To investigate this, we complemented our biochemical experiments with single particle measurements by AFM. This analysis was conducted in liquid, allowing us to identify and characterize the structure and height of the different particles under experimentally relevant conditions (Fig. 5A and B). PC and ES particles were spherical with heights of $50 \pm 1 \mathrm{~nm}$ and $48 \pm 1 \mathrm{~nm}$, respectively (black and red bars, Fig. 5B and Table 3 ). These values correspond to $86 \%$ and $83 \%$ of particle diameter as reported by cryo-EM [62], suggesting that capsids were deformed by contact with the surface. This observation is consistent with another study on P22 VLPs [24]. The EX particles presented a more faceted appearance and their orientation could be resolved (for example, the EX capsids shown in Fig. 5A were adsorbed along the 5 -fold symmetry axis (S5)). EX particles presenting a S5 orientation were higher than particles sitting on the 2- or 3-fold axes. This trend disappeared for WB particles, for which the three orientations presented similar heights (Fig. 5B).

Stiffness and brittleness are important material properties and can be measured by nano-indentation. This entails deforming individual particles with an AFM tip until the capsid breaks [52]. The deformation of the particle (indentation) is registered as a function of the force applied, which leads to the force-indentation curve (FIC) [82]. Fig. 5C shows four examples of FICs. These FICs correspond to the deformation and breakage of the particles shown in panel 5A (left and right, particles before and after breakage). From each FIC, a value of stiffness (elastic constant, k) and brittleness (critical strain, $\varepsilon_{\text {critical }}$ can be obtained [83]. High values of $\varepsilon_{\text {critical }}$ indicate that the particle can withstand large deformations without rupturing, whereas low values are characteristic of brittle materials. Similarly, high values of stiffness indicate that more force is required to cause deformation.

No significant changes in the mechanical properties were observed after scaffold protein removal (black and red bars, Fig. 5D and E). However, after expansion, particles increased in rigidity and brittleness (blue bars, Fig. 5D and E). WB particles were less rigid, as predicted by continuum elasticity theory, [33] and their capsids were less brittle.

\subsection{Hydrogen-deuterium exchange of P22 capsids}

Each of the biophysical analyses performed showed a consistent increase in capsid stability up to the EX form. We hypothesized that changes in the hydrogen bonding network within and between protein subunits were responsible. This could explain the increased stability of the hydrophobic core as well. To test this, hydrogen deuterium exchange mass spectrometry (HDX-MS) was used. HDX-MS is a straightforward and versatile technique for probing the stability of protein hydrogen bonding and dynamics of protein complexes [6,53,54]. P22 particles were rapidly diluted 10 -fold in a buffered solution of $\mathrm{D}_{2} \mathrm{O}$. The incorporation of deuterium was measured over time using LCMS [84], with the rate and extent of deuterium uptake inversely correlating with hydrogen bond stability. The P22 coat protein had a measured mass of $46,620 \mathrm{Da}$ (expected 46,620). After dilution in $\mathrm{D}_{2} \mathrm{O}$, a rapid uptake of deuterium was observed for all four morphologies during the first $5 \mathrm{~min}$ of exchange (Fig. 6A). EX showed the least uptake in comparison with others. The 0-5-min time window represents fast exchanging regions. Fast exchange is generally attributed to solvent exposed and dynamic domains. These are often coils, loops, and regions undergoing conformational change that lack stable hydrogen bonding [85,86]. After one hour of exchange, PC and WB had a significantly greater level of exchange than ES and EX. The later time points report on medium to slow exchanging amide protons, providing information on protein regions with greater hydrogen bond stability. The reaction was followed for $12 \mathrm{~h}$ to ensure that slow exchanging regions, those with the most stable hydrogen bonding networks, were accounted for. Slow exchanging regions report on well-ordered secondary, tertiary, and quaternary structures. At $12 \mathrm{~h}$, samples had a progressive decrease in exchange from PC > ES > EX, with 18 additional residues per subunit protected on average (Fig. 6B). The observed decrease in exchange is in agreement with our hypothesis that maturation leads to a more stable hydrogen bonding network across the capsid. However, WB showed an increase in exchange compared to EX. This observation was initially unexpected due to the fact that WB showed a higher $\mathrm{T}_{\mathrm{m}}$ and resistance to chemical denaturation. We believe this is due to the absence of
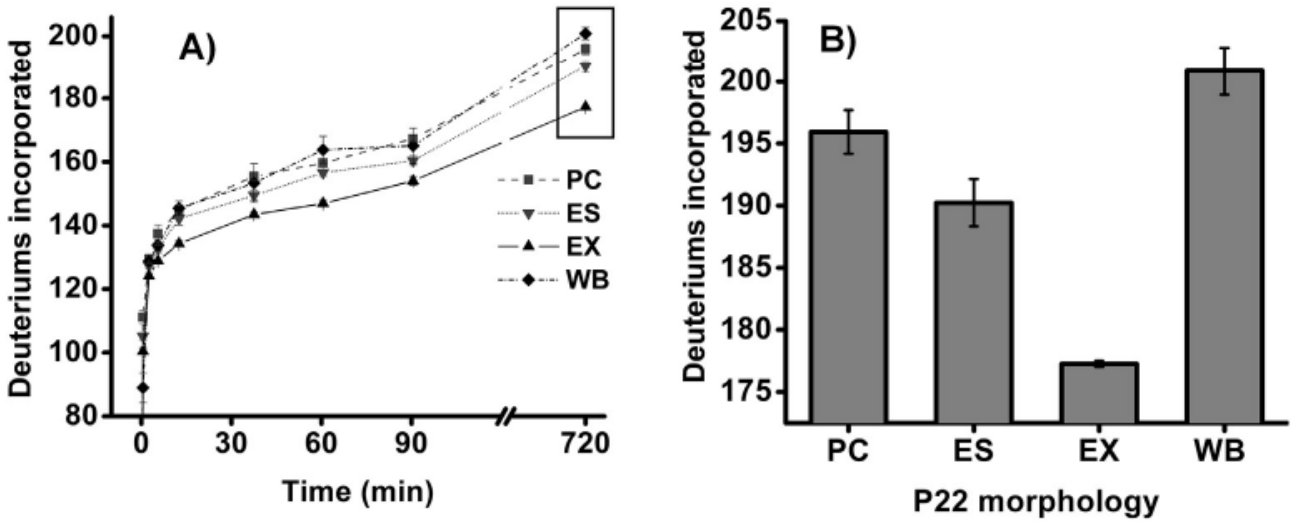

Fig. 6. Intact protein hydrogen deuterium exchange mass spectrometry of $\mathrm{P} 22$ particles. PC, ES, EX \& WB were diluted in $10 \mathrm{mM}$ ammonium bicarbonate, $50 \mathrm{mM} \mathrm{NaCl} \mathrm{D}_{2} \mathrm{O}$ buffer, pH 7.0. (A) Number of deuterium incorporated (y-axis) along with incubation time (x-axis) for coat protein. (B) Total number of deuteriums exchanged after $12 \mathrm{~h}$. Total exchange reactions were carried out for $12 \mathrm{~h}$ and done in three technical replicates. Error bars represent \pm SD. 
pentamers, which increases the average solvent accessible surface area, making direct comparisons between WB and other forms difficult to interpret by HDX-MS.

\subsection{Maturation increases solvent excluded area}

If our hypothesis that a well-established hydrophobic core and a more robust hydrogen bonding network is ultimately responsible for the increased stability of P22 capsids as they mature, there should be evidence for this in the structural models. Models of P22 from cryo-EM at $4.0 \AA$ resolution showed that the change in the morphology from PC to EX involved a change from skewed to symmetric hexamers [62]. Symmetric hexamers create a consistent interaction surface across hexameric and pentameric capsomers and allow additional interactions in the E loop (G60-A67) and P domain (G396-S402) as well [62]. This is suggestive of increased global interactions in the mature capsid. However, a direct analysis of subunit interfaces and solvent excluded surfaces had not been completed. To do this, we analyzed changes in quaternary organization, paying specific attention to the total solvent excluded surface area (SESA) of each P22 form. Two sets of cryo-EM based structural models from two different labs were used for this analysis. Due to the requirement for side chain density to accurately estimate SESA, the cryo_EM models (PDB files 2xyy, 2xyz [62] 3iyi, 3iyh [39]) were submitted to Phyre2 [63] and Modrefiner [64] for side chain modeling and secondary structure refinement.

The two data sets represented different morphological pairs corresponding to PC and EX [62] and PC and WB [64]. We compared the refined models for EX and WB with their respective PC partner (2xyy with $2 x y z$ and 3iyi with 3iyh). Our goal was to make global comparisons that took into account the quaternary structural components and would match closely to the global biophysical data above. This approach would also de-emphasize differences specific to the respective pairs of models. Fig. $7 \mathrm{~A}$ and B show the subunit groups from different cryo-EM models used in the SESA calculations. Panel C shows the relative difference in SESA values at regular (I) and quasi-equivalent (Q) axes for the two pairs (See Fig. S2 for details). The numerical values of SESA $\left(\AA^{2}\right)$ were obtained for different subunits and percent change is calculated by subtracting SESA $\left(\AA^{2)}\right.$ unexpanded from expanded form and divided by total SESA $\left(\AA^{2}\right)$ (Supplementary Table S1, Fig. 7C). Percent positive change shows higher SESA after maturation, that further indicates higher order of inter-coat protein interactions. Comparative analysis of PC: 2xyy and EX: 2xyz showed an increase in SESA at both regular icosahedral and quasi-equivalent axis: I3 (2.2\%), I5 (7.7\%), Q3 (5.0\%), Q5 (7.7\%) and Q6 (2.4\%). The comparison of PC: 3iyi and WB: 3iyh showed I3 (12.0\%), Q3 (1\%), Q5 (20\%) and Q6 $(8.8 \%)$. However, the comparison of PC: 3iyi and WB: 3iyh showed a decrease in SESA at Q-3 and I-5. This was expected because WB lacks pentamers, so residues facing the I-5 axis are more solvent accessible. This is consistent with our HDX on WB, where an increase in exchange was observed (Fig. 6). Despite lacking pentamers, WB shows a higher SESA in all other axes. This confirms that each subunit in the mature form contributes more to the central hydrophobic core than in its procapsid counterpart. Our experimental observations are supported by a computational study on multiple icosahedral viruses (deposited in VIPER databases), where they have proposed that virus assembly may be driven by burying hydrophobic surface area at inter-protein surfaces [87,88]. A study involving computational analysis of quaternary interactions in icosahedral viruses demonstrated that the association energy is an indicator of stabilities at quasi-equivalent interfaces [89]. We extracted the association energy from VIPER [90] and compared across both models (PC:2xyy and EX:2xyz, PC:3iyi and WB:3iyh) at common interfaces. There is a significant increase in calculated association energy of EX and WB, the two forms that are quasi-equivalent (Table S2A, S2B). Inspecting our SESA calculations along with the AFM results, we suggest that an increase in intra-protein hydrophobic interactions due to capsid expansion lead to a more rigid and brittle EX particle. After removal of the 5-fold subunits, a substantial loss in terms of SESA, the WB particle has a comparable rigidity but significantly lower brittleness. In WB, intra-protein interactions are concentrated around the icosahedral and quasi-icosahedral 3-fold and 5-fold axes. Interestingly, in both SESA comparisons, we observed an increase in the solvent accessibility at I2 and Q2 axes. A previous study on human Adenovirus found that the two fold axis is the stiffest in the capsid [91]. The SESA calculations are consistent with the idea that mechanical anisotropy arising from structural differentiation at axes of symmetry contributes to the capsid stiffness [92]. During the preparation of this manuscript, an atomic resolution cryoEM structure of the P22 mature capsid (PDB: 5UU5) was released [48]. Calculations revealed that the new EX structure had greater SESA due to the inclusion of more electron density in the final model. However, the overall trend remained the same.

\subsection{Maturation stabilizes capsids by enhancing quaternary interaction}

The maturation of P22 capsids has been under investigation for several decades, however, the spatial arrangement of coat proteins en route to maturation that leads to the specific biophysical attributes in the context of thermodynamics hasn't been discussed. Since the maturation event is irreversible and thermodynamics tells us only about states, we have discussed the PC, ES, EX and WB as metastable forms occupying separate energy wells. These wells are separated by an activation energy/kinetic barrier which can be overcome by specific temperature and/or chemical triggers. Therefore, we combined the data collected here to produce an energy landscape model. (Fig. 8). Positions lower on the plot have lower free energy (greater thermodynamic stability). A series of local energy minima are shown as shallow wells, the width of which reflects the conformational freedom as measured for each form. Broad energy wells represent structures with relatively greater flexibility, while a narrow energy well represents a more rigid structure. Based on our results, the conformational ensemble representing PC and ES are shown as broad energy wells. This is supported by their greater solvent accessibility (measured by HDX-MS) and lower rigidity (measured by AFM). The DSF and HDX data show ES to be more stable than PC. Therefore, ES occupies a lower position than PC on the free energy axis (Fig. 8). Our results indicate EX is more stable than ES, thus it is lower again on Fig. 8. The narrow energy well for EX reflects the higher stability, rigidity, brittleness and relative increase in SESA as revealed by DSF, HDX, AFM and structural models, respectively.

An important question remains about the driving force mediating the transition from spherical to icosahedral form. Our intact protein HDX-MS indicated a net increase in hydrogen bond network stability, a finding that was not included in previous HDX studies that focused on exchange in specific regions $[93,94]$. This suggests an enthalpic contribution to maturation which is supported by an earlier DSC study which found a negative change in enthalpy was associated with expansion [26]. Calculation of SESA from structural models showed a relative increase after maturation indicating an increased hydrophobic contribution to the shell after maturation. When hydrophobic regions are buried and excluded from solvent, it results in the release of bound water with a net increase in the system entropy at the expense of a local reduction in entropy. Therefore, we now suggest that the change in P22 morphology from PC to EX (maturation) is mediated by both enthalpy and entropic driven factors.

The WB which has lost its pentamers, eliminating protein-protein interactions at five-fold axes, remarkably remains resistant to heat and denaturant. But it is less rigid and exchanges more deuterium than EX (Figs. 5 \& 6). Limited proteolysis of WB shows that release of pentamers exposes a cleavage site to Trypsin [39], analogous to the increased exchange. The increased deformability could be indicative of conformational entropy which balances the lost inter-subunit interactions. WB is the most stable form of P22 to heat and chemical stress, which may seem surprising given the net loss of subunit contact area, but in 

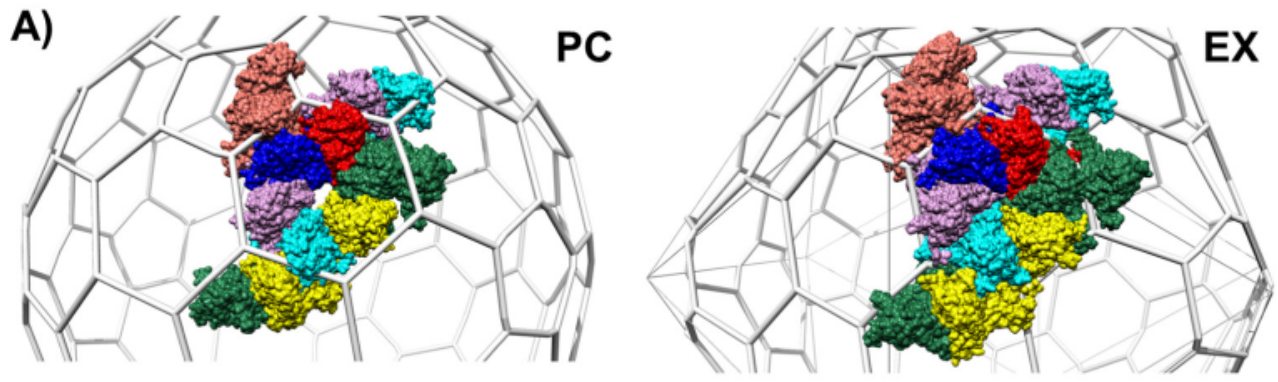

Fig. 7. Solvent excluded surface area (SESA) of P22 capsids. (A) Spacing filling models of selected subunits show the transformation between PC: 2xyy and EX: 2xyz ${ }^{54}$ (B) Spacing filling models of PC: 3iyi and WB: 3 iyh ${ }^{38}$ display the transition from PC to WB. Absence of pentamers is observed around fivefold axis in WB. Solvent excluded surface area (SESA) was computed with a probe radius of $\sim 1.4 \AA$ using UCSF Chimera software 103 after the addition of side chain density. (C) Percent difference in SESA is calculated and compared across both pairs (2xyy and
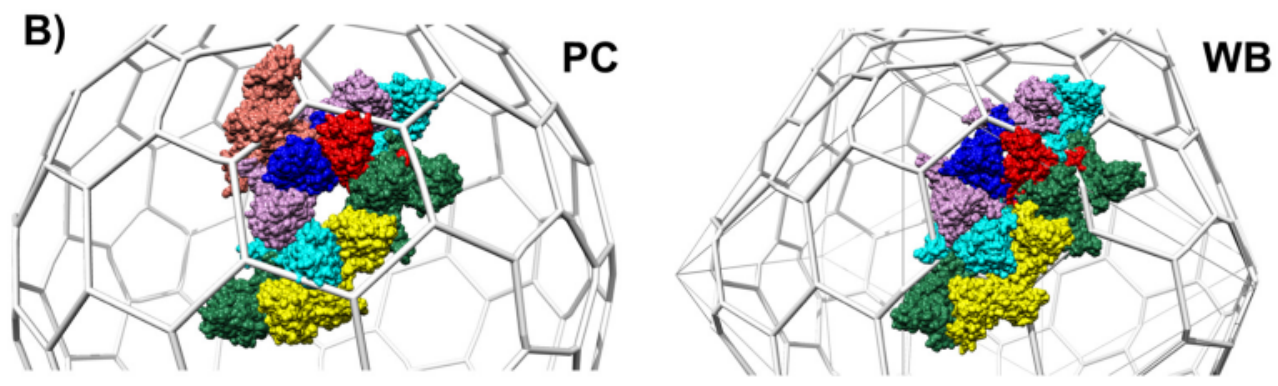
2xyz, black color column bar) and (3iyi and 3iyh, grey column bar) along with regular icosahedral axes (I) at 2, 3 and 5 fold and quasi-equivalent (Q) at 2, 3, 5 and 6 fold axes. Numeric SESA values $\left(\AA^{2}\right)$ is calculated for each axis by averaging all the interacting subunit SESA values at a given axis (Table S2). Asterisk * at I-5 indicates a reduction in SESA for WB.

C)

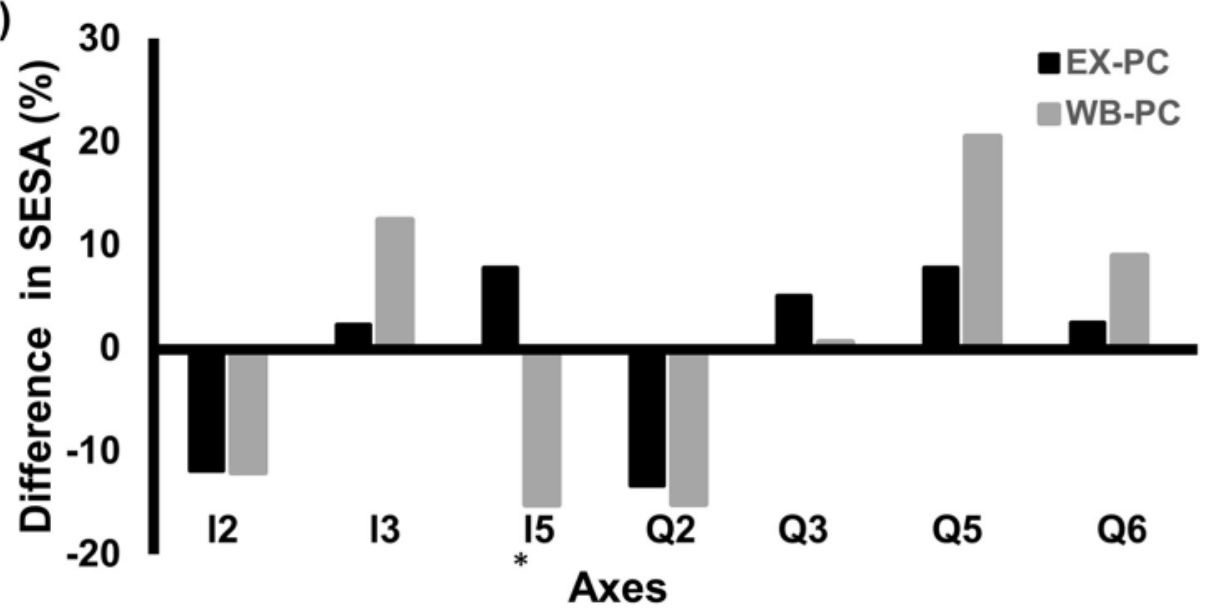

the context of icosahedra, pentamers represent defects in the hexagonal lattice. The existence of WB elegantly demonstrates the complexity inherent in capsid protein interactions and the emergent properties that can arise from icosahedral symmetry.

Finally, we can summarize that the assembly and maturation program for P22 is encoded in the amino acid sequence of the coat protein and is regulated by a two-step mechanism. The first step in assembly is initiated using relatively weak interactions between coat subunits and scaffold proteins leading to a spherical procapsid (PC). Weak interactions are a critical requirement for the precise positioning of coat proteins to avert the formation of aberrant structures and kinetic traps. Hence, the procapsid represents a higher energy local minimum enroute to the more stable expanded forms. The second step in the process is dictated by quatemary interactions and rules of quasi-equivalence (EX/WB) which require subunits to inhabit non-identical local environments. This step is achieved through conformational switching once expansion is initiated.

\section{Conclusion}

The thermodynamics and molecular mechanisms driving assembly and maturation of icosahedral virus capsids are complex. Bacteriophage capsids are faced with a difficult challenge in that they must increase stability as they expand. In a cell, this is triggered by DNA packaging and in many cases, requires protein-DNA interactions to gain stability. Through the use of orthogonal analytical techniques involving single particle and population based methods, we have now worked out a model that can be used to discuss general and specific features of expansion mediated icosahedral capsid maturation. P22 manages this thermodynamic balancing act without the aid of covalent cross-linking, which is used by HK97. The general biomechanical transformations described here for P22 provide a model for other viral systems which including dsDNA viruses such as adeno and herpes. These findings can also guide design programs for the development of icosahedral capsids as nanomaterials and containers where tunable stability and rigidity are of significant value.

\section{Transparency document}

The Transparency document associated with this article can be found, in the online version. 


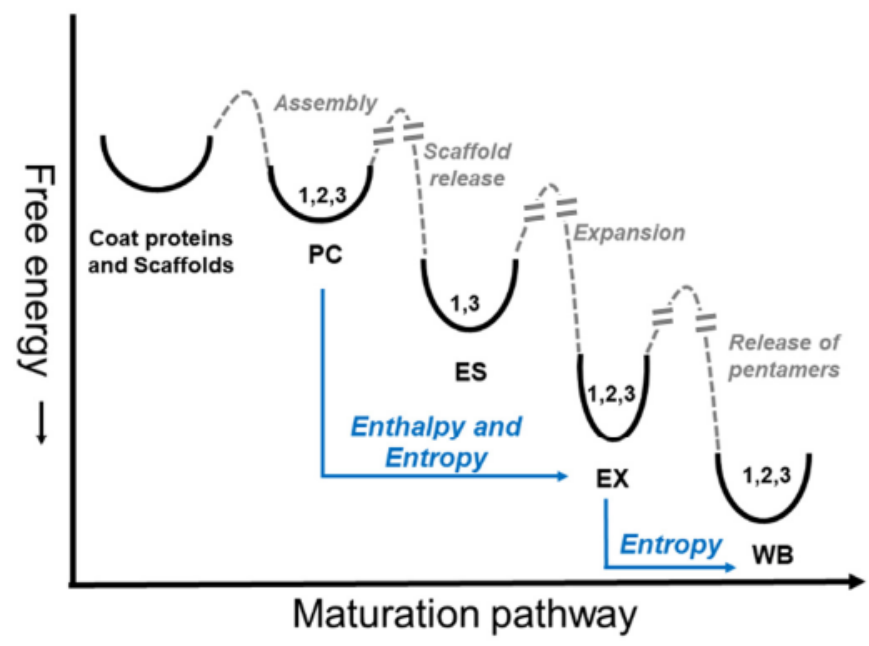

Fig. 8. Schematic energy landscape of P22 maturation. Y-axis is free energy and the $\mathrm{X}$-axis is the direction of maturation. Grey line represents the height of kinetic barrier. The height of kinetic barriers between coat proteins and PC is presumably low as assembly proceeds spontaneous readily both in vivo and in vitro condition. The height of the kinetic barriers between different stages are not precisely known, but the kinetic barriers are presumably high as transition to next form is not spontaneous rather it requires the presence of denaturant/ heat/or, in vivo DNA packaging. The broader minima for PC and ES indicate the morphology to less protected and less rigid. The sharp minimum for EX reflects the higher rigidity and lowest deuterium exchange. Biophysical methods supporting the energy landscape are shown by different numbers: DSF (1), AFM (2), HDX (3). Blue color line represents the driving mechanism stabilizing the corresponding transition.

\section{Acknowledgements}

The authors would like to thank Jonathan K. Hilmer for technical support with Mass Spectrometry and Liam Scott for critical reading of the manuscript. The Proteomics, Metabolomics, and Mass Spectrometry Facility at MSU has received support from the Murdock Charitable Trust and National Institute of General Medical Sciences of the National Institutes of Health under Award Number P20GM103474. This work was made possible in part by funding to BB from the National Institutes of Health NIAID AI081961-01A1. PJ. P and A. Ll. Acknowledge projects FIS2014-59562-R, FIS2015-71108-REDT, Fundación BBVA and "María de Maeztu" Program for Units of Excellence in R\&D (MDM-2014-0377).

\section{Appendix A. Supplementary data}

Supplementary data to this article can be found online at https:// doi.org/10.1016/j.bbagen.2018.03.006.

\section{References}

[1] A. Zlotnick, Are weak protein-protein interactions the general rule in capsid assembly? Virology 315 (2003) 269-274, http://dx.doi.org/10.1016/S00426822(03)00586-5.

[2] P. Ceres, A. Zlotnick, Weak protein-protein interactions are sufficient to drive assembly of hepatitis B virus capsids, Biochemistry 41 (2002) 11525-11531, http:// dx.doi.org/10.1021/bi0261645.

[3] A. Zlotnick, Theoretical aspects of virus capsid assembly, J. Mol. Recognit. 18 (2005) 479-490, http://dx.doi.org/10.1002/jmr.754.

[4] B. Bothner, D. Taylor, B. Jun, K.K. Lee, G. Siuzdak, C.P. Schultz, C.P. Schlutz, J.E Johnson, Maturation of a tetravirus capsid alters the dynamic properties and creates a metastable complex, Virology 334 (2005) 17-27, http://dx.doi.org/10. 1016/j.virol.2005.01.017.

[5] J.F. Conway, W.R. Wikoff, N. Cheng, R.L. Duda, R.W. Hendrix, J.E. Johnson, A.C. Steven, Virus maturation involving large subunit rotations and local refolding, Science 292 (2001) 744-748, http://dx.doi.org/10.1126/science.1058069.

[6] R. Tuma, L.U. Coward, M.C. Kirk, S. Barnes, P.E.P. Jr, B. Al, Exchange as a Probe of Folding and Assembly in Viral Capsids, (2001), pp. 389-396, http://dx.doi.org/10. 1006/jmbi.2000.4383.

[7] W.H. Roos, I. Gertsman, E.R. May, C.L. Brooks, J.E. Johnson, G.J.L. Wuite,
Mechanics of bacteriophage maturation, Proc. Natl. Acad. Sci. 109 (2012) 2342-2347, http://dx.doi.org/10.1073/pnas.1109590109.

[8] J. De Sena, W.R. Heifner, N.S. Stolov, Studies on the in vitro uncoating of poliovirus. IV. Characteristics of solubilized membrane-modifying and -stabilizing factors, Virology 128 (1983) 354-365, http://dx.doi.org/10.1016/0042-6822(83) 90262-3.

[9] J.M. Hogle, Poliovirus cell entry: common structural themes in viral cell entry pathways, Annu. Rev. Microbiol. 56 (2002) 677-702, http://dx.doi.org/10.1146/ annurev.micro.56.012302.160757.

[10] P.E. Prevelige Jr., D. Thomas, K.L. Aubrey, S.A. Towse, G.J. Thomas Jr., Subunit conformational changes accompanying bacteriophage P22 capsid maturation, Biochemistry 32 (1993) 537-543.

[11] J.K. Lewis, B. Bothner, T.J. Smith, G. Siuzdak, Antiviral agent blocks breathing of the common cold virus, Proc. Natl. Acad. Sci. U. S. A. 95 (1998) 6774-6778, http:// dx.doi.org/10.1073/pnas.95.12.6774.

[12] J.A. Speir, B. Bothner, C. Qu, D.A. Willits, M.J. Young, J.E. Johnson, Enhanced local symmetry interactions globally stabilize a mutant virus capsid that maintains infectivity and capsid dynamics, J. Virol. 80 (2006) 3582-3591, http://dx.doi.org/10. 1128/JVI.80.7.3582-3591.2006.

[13] J. Lin, L.Y. Lee, M. Roivainen, D.J. Filman, J.M. Hogle, D.M. Belnap, Structure of the fab-labeled "breathing" state of native poliovirus, J. Virol. 86 (2012) 5959-5962, http://dx.doi.org/10.1128/JVI.05990-11.

[14] R. Frey, T. Hayashi, D. Hilvert, Enzyme-mediated polymerization inside engineered protein cages, Chem. Commun. 52 (2016) 10423-10426, http://dx.doi.org/10. 1039/C6CC05301 G.

[15] A.M. ElSohly, C. Netirojjanakul, I.L. Aanei, A. Jager, S.C. Bendall, M.E. Farkas, G.P. Nolan, M.B. Francis, Synthetically modified viral capsids as versatile carriers for use in antibody-based cell targeting, Bioconjug. Chem. 26 (2015) 1590-1596, http://dx.doi.org/10.1021/acs. bioconjchem.5b00226.

[16] D. Patterson, E. Edwards, T. Douglas, Hybrid Nanoreactors: coupling enzymes and small-molecule catalysts within virus-like particles, Isr. J. Chem. 55 (2015) 96-101, http://dx.doi.org/10.1002/ijch.201400092.

[17] D.P. Patterson, B. Schwarz, K. El-Boubbou, J. van der Oost, P.E. Prevelige, T. Douglas, Virus-like particle nanoreactors: programmed encapsulation of the thermostable CelB glycosidase inside the P22 capsid, Soft Matter 8 (2012) 10158, , http://dx.doi.org/10.1039/c2sm26485d.

[18] R.J. Usselman, S. Qazi, P. Aggarwal, S.S. Eaton, G.R. Eaton, S. Russek, T. Douglas, Gadolinium-loaded viral capsids as magnetic resonance imaging contrast agents, Appl. Magn. Reson. 46 (2015) 349-355, http://dx.doi.org/10.1007/s00723-0140639-y.

[19] S. Qazi, H.M. Miettinen, R.A. Wilkinson, K. McCoy, T. Douglas, B. Wiedenheft, Programmed Self-Assembly of an Active P22-Cas 9Nanocarrier System, Mol. Pharm. 13 (2016) 1191-1196, http://dx.doi.org/10.1021/acs.molpharmaceut.5b00822.

[20] S. Kang, M. Uchida, A. O'Neil, R. Li, P.E. Prevelige, T. Douglas, Implementation of p22 viral capsids as nanoplatforms, Biomacromolecules 11 (2010) 2804-2809, http://dx.doi.org/10.1021/bm100877q.

[21] A. O'Neil, C. Reichhardt, B. Johnson, P.E. Prevelige, T. Douglas, Genetically programmed in vivo packaging of protein cargo and its controlled release from bacteriophage P22, Angew. Chem. Int. Ed. 50 (2011) 7425-7428, http://dx.doi.org/ 10.1002/anie.201102036.

[22] D.P. Patterson, B. Schwarz, R.S. Waters, T. Gedeon, T. Douglas, Encapsulation of an enzyme cascade within the bacteriophage P22 virus-like particle, ACS Chem. Biol. 9 (2014) 359-365, http://dx.doi.org/10.1021/cb4006529.

[23] S. Kang, L.M. Oltrogge, C.C. Broomell, L.O. Liepold, P.E. Prevelige, M. Young, T. Douglas, Controlled assembly of bifunctional chimeric protein cages and composition analysis using noncovalent mass spectrometry, J. Am. Chem. Soc. 130 (2008) 16527-16529, http://dx.doi.org/10.1021/ja807655t.

[24] A. Llauró, B. Schwarz, R. Koliyatt, P.J. de Pablo, T. Douglas, Tuning viral capsid nanoparticle stability with symmetrical morphogenesis, ACS Nano 10 (2016) 8465-8473, http://dx.doi.org/10.1021/acsnano.6b03441.

[25] S. Casjens, E. Wyckoff, M. Hayden, L. Sampson, K. Eppler, S. Randall, E.T. Moreno, P. Serwer, Bacteriophage P22 portal protein is part of the gauge that regulates packing density of intravirion DNA, J. Mol. Biol. 224 (1992) 1055-1074, http://dx. doi.org/10.1016/0022-2836(92)90469-Z.

[26] M.L. Galisteo, J. King, Conformational transformations in the protein lattice of phage P22 procapsids, Biophys. J. 65 (1993) 227-235, http://dx.doi.org/10.1016/ S0006-3495(93)81073-7.

[27] M.H. Parker, P.E. Prevelige, Electrostatic interactions drive scaffolding/coat protein binding and procapsid maturation in bacteriophage P22, Virology 250 (1998) 337-349, http://dx.doi.org/10.1006/viro.1998.9386.

[28] W. Earnshaw, S. Casjens, S.C. Harrison, Assembly of the head of bacteriophage P22: X-ray diffraction from heads, proheads and related structures, J. Mol. Biol. 104 (1976) 387-410, http://dx.doi.org/10.1016/0022-2836(76)90278-3.

[29] A Discussion on the assembly of regular viruses - Structure and assembly of the capsid of bacteriophage P22, Philos. Trans. R. Soc. Lond. Ser. B Biol. Sci. 276 (1976) 37 LP-49 http://rstb.royalsocietypublishing.org/content/276/943/37.abstract.

[30] S. Casjens, M.B. Adams, C. Hall, J. King, Assembly-controlled autogenous modulation of bacteriophage P22 scaffolding protein gene expression, J. Virol. 53 (1985) 174-179 http://www.ncbi.nlm.nih.gov/pmc/articles/PMC255002/.

[31] P.E. Prevelige, D. Thomas, J. King, Scaffolding protein regulates the polymerization of P22 coat subunits into icosahedral shells in vitro, J. Mol. Biol. 202 (1988) 743-757, http://dx.doi.org/10.1016/0022-2836(88)90555-4.

[32] J.E. Johnson, Functional implications of protein-protein interactions in icosahedral viruses, Proc. Natl. Acad. Sci. 93 (1996) 27-33, http://dx.doi.org/10.1073/pnas. 93.1.27.

[33] J. Lanman, R. Tuma, P.E. Prevelige, Identification and characterization of the 
domain structure of bacteriophage P22 coat protein, Biochemistry 38 (1999) 14614-14623 http://www.ncbi.nlm.nih.gov/pubmed/10545185.

[34] C.M. Capen, C.M. Teschke, Folding defects caused by single amino acid substitutions in a subunit are not alleviated by assembly, Biochemistry 39 (2000) 1142-1151, http://dx.doi.org/10.1021/bi991956t.

[35] M. Tatnall, J. King, Purification of the coat and scaffolding procapsids of bacteriophage proteins from, 547 (1981) 529-547.

[36] S. Casjens, M.B. Adams, C. Hall, J. King, Autogenous modulation of Bacteriophage, 123 (1985) 174-179.

[37] C.M. Teschke, A. McGough, P.A. Thuman-Commike, Penton release from P22 heatexpanded capsids suggests importance of stabilizing penton-hexon interactions during capsid maturation, Biophys. J. 84 (2003) 2585-2592, http://dx.doi.org/10. 1016/S0006-3495(03)75063-2.

[38] J. Lucon, S. Qazi, M. Uchida, G.J. Bedwell, B. Lafrance, P.E.P. Jr, T. Douglas, Polymerization with high-density cargo loading, 4 (2012) 781-788, http://dx.doi. org/10.1038/NCHEM.1442.

[39] K.N. Parent, R. Khayat, L.H. Tu, M.M. Suhanovsky, J.R. Cortines, C.M. Teschke, J.E Johnson, T.S. Baker, P22 coat protein structures reveal a novel mechanism for capsid maturation: stability without auxiliary proteins or chemical crosslinks, Structure 18 (2010) 390-401, http://dx.doi.org/10.1016/j.str.2009.12.014.

[40] G.J. Bedwell, Z. Zhou, M. Uchida, T. Douglas, A. Gupta, P.E Prevelige, Selective Biotemplated synthesis of TiO2 inside a protein cage, Biomacromolecules 16 (2015) 214-218, http://dx.doi.org/10.1021/bm501443e.

[41] D.P. Patterson, A. Rynda-Apple, A.L. Harmsen, A.G. Harmsen, T. Douglas, Biomimetic antigenic nanoparticles elicit controlled protective immune response to influenza, ACS Nano 7 (2013) 3036-3044, http://dx.doi.org/10.1021/nn4006544.

[42] J.C.-Y. Wang, C. Chen, V. Rayaprolu, S. Mukhopadhyay, A. Zlotnick, Self-assembly of an alphavirus Core-like particle is distinguished by strong Intersubunit association energy and structural defects, ACS Nano 9 (2015) 8898-8906, http://dx.doi. org/10.1021/acsnano.5b02632.

[43] J.A. Speir, S. Munshi, G. Wang, T.S. Baker, J.E. Johnson, Structures of the native and swollen forms of cowpea chlorotic mottle virus determined by X-ray crystallography and cryo-electron microscopy, Structure 15 (1995) 63-78, http://dx.doi. org/10.1016/S0969-2126(01)00135-6.

[44] R.W. Hendrix, J.E. Johnson, Viral Molecular Machines, 726 (2012), pp. 351-363, http://dx.doi.org/10.1007/978-1-4614-0980-9.

[45] W.R. Wikoff, L. Liljas, R.L. Duda, H. Tsuruta, R.W. Hendrix, J.E. Johnson, Topologically linked protein rings in the bacteriophage HK97 capsid, Science 289 (2000) 2129-2133, http://dx.doi.org/10.1126/science.289.5487.2129.

[46] R.L. Duda, Protein chainmail: Catenated protein in viral capsids, Cell 94 (1998) 55-60, http://dx.doi.org/10.1016/S0092-8674(00)81221-0.

[47] R. Tuma, P.E. Prevelige, G.J. Thomas, Mechanism of capsid maturation in a doublestranded DNA virus, Proc. Natl. Acad. Sci. U. S. A. 95 (1998) $9885-9890$ http:// www.pubmedcentral.nih.gov/articlerender.fcgi $?$ artid $=3274788 \&$ tool $=$ pmcentrez \&rendertype $=$ abstract.

[48] C.F. Hryc, D.-H. Chen, P.V. Afonine, J. Jakana, Z. Wang, C. Haase-Pettingell, W. Jiang, P.D. Adams, J.A. King, M.F. Schmid, W. Chiu, Accurate model annotation of a near-atomic resolution cryo-EM map, Proc. Natl. Acad. Sci. (2017) 201621152, , http://dx.doi.org/10.1073/pnas.1621152114.

[49] V. Rayaprolu, S. Kruse, R. Kant, N. Movahed, D. Brooke, Fluorometric estimation of viral thermal stability, 15 (4) (2014), http://dx.doi.org/10.21769/BioProtoc.1199.

[50] V. Rayaprolu, S. Kruse, R. Kant, B. Venkatakrishnan, N. Movahed, D. Brooke, B. Lins, A. Bennett, T. Potter, R. McKenna, M. Agbandje-McKenna, B. Bothner, Comparative analysis of adeno associated virus capsid stability and dynamics, $\mathrm{J}$. Virol. (2013), http://dx.doi.org/10.1128/JVI.01415-13.

[51] M.G. Mateu, Assembly, engineering and applications of virus-based protein nanoparticles, Adv. Exp. Med. Biol. 940 (2016) 83-120, http://dx.doi.org/10.1007/978 3-319-39196-0 5.

[52] F. Moreno-Madrid, N. Martin-Gonzalez, A. Llauro, A. Ortega-Esteban, M. HernandoPerez, T. Douglas, I.A.T. Schaap, P.J. de Pablo, Atomic force microscopy of virus shells, Biochem. Soc. Trans. 45 (2017) 499-511, http://dx.doi.org/10.1042/ BST20160316.

[53] R. Kant, B. Zeng, C.J. Thomas, B. Bothner, S.R. Sprang, Ric-8A, a G protein chaperone with nucleotide exchange activity induces long-range secondary structure changes in Ga, elife 5 (2016) e19238, , http://dx.doi.org/10.7554/eLife.19238.

[54] M. van de Waterbeemd, A. Llauro, J. Snijder, A. Valbuena, A. Rodriguez-Huete, M.A. Fuertes, P.J. de Pablo, M.G. Mateu, A.J.R. Heck, Structural analysis of a temperature-induced transition in a viral capsid probed by HDX-MS, Biophys. J. 112 (2017) 1157-1165, http://dx.doi.org/10.1016/j.bpj.2017.02.003.

[55] C. Carrasco, A. Carreira, I.A.T. Schaap, P.A. Serena, J. Gómez-Herrero, M.G. Mateu, P.J. de Pablo, DNA-mediated anisotropic mechanical reinforcement of a virus, Proc. Natl. Acad. Sci. 103 (2006) 13706-13711, http://dx.doi.org/10.1073/pnas. 0601881103.

[56] W. Jiang, Z. Li, Z. Zhang, M.L. Baker, P.E. Prevelige, W. Chiu, Coat protein fold and maturation transition of bacteriophage P22 seen at subnanometer resolutions, Nat. Struct. Biol. 10 (2003) 131-135, http://dx.doi.org/10.1038/nsb891.

[57] A. Ortega-Esteban, I. Horcas, M. Hernando-Pérez, P. Ares, A.J. Pérez-Berná, C. San Martín, J.L. Carrascosa, P.J. de Pablo, J. Gómez-Herrero, Minimizing tip-sample forces in jumping mode atomic force microscopy in liquid, Ultramicroscopy 114 (2012) 56-61, http://dx.doi.org/10.1016/j.ultramic.2012.01.007.

[58] J.E Sader, J.W.M. Chon, P. Mulvaney, Calibration of rectangular atomic force microscope cantilevers, Rev. Sci. Instrum. 70 (1999) 3967-3969, http://dx.doi.org/ 10.1063/1.1150021.

[59] I.L. Ivanovska, P.J. de Pablo, B. Ibarra, G. Sgalari, F.C. MacKintosh, J.L. Carrascosa, C.F. Schmidt, G.J.L. Wuite, Bacteriophage capsids: tough nanoshells with complex elastic properties, Proc. Natl. Acad. Sci. U. S. A. 101 (2004) 7600-7605, http://dx. doi.org/10.1073/pnas.0308198101.

[60] I. Horcas, R. Fernández, J.M. Gómez-Rodríguez, J. Colchero, J. Gómez-Herrero, A.M. Baro, WSXM: a software for scanning probe microscopy and a tool for nanotechnology, Rev. Sci. Instrum. 78 (2007) 0-8, http://dx,doi.org/10.1063/1. 2432410.

[61] M. Hernando-Pérez, S. Lambert, E. Nakatani-Webster, C.E Catalano, P.J. de Pablo, Cementing proteins provide extra mechanical stabilization to viral cages, Nat. Commun. 5 (2014) 4520, , http://dx.doi.org/10.1038/ncomms5520.

[62] D.-H. Chen, M.L. Baker, C.F. Hryc, F. DiMaio, J. Jakana, W. Wu, M. Dougherty, C. Haase-Pettingell, M.F. Schmid, W. Jiang, D. Baker, J.A. King, W. Chiu, Structural basis for scaffolding-mediated assembly and maturation of a dsDNA virus, Proc. Natl. Acad. Sci. U. S. A. 108 (2011) 1355-1360, http://dx.doi.org/10.1073/pnas. 1015739108.

[63] L.A. Kelley, S. Mezulis, C.M. Yates, M.N. Wass, M.J.E. Sternberg, The Phyre2 web portal for protein modeling, prediction and analysis, Nat. Protoc. 10 (2015) 845-858, http://dx.doi.org/10.1038/nprot.2015.053.

[64] D. Xu, Y. Zhang, Improving the physical realism and structural accuracy of protein models by a two-step atomic-level energy minimization, Biophys. J. 101 (2011) 2525-2534, http://dx.doi.org/10.1016/j.bpj.2011.10.024.

[65] E.F. Pettersen, T.D. Goddard, C.C. Huang, G.S. Couch, D.M. Greenblatt, E.C. Meng T.E. Ferrin, UCSF chimera - a visualization system for exploratory research and analysis, J. Comput. Chem. 25 (2004) 1605-1612, http://dx.doi.org/10.1002/jcc. 20084.

[66] S. Hafenstein, L.M. Palermo, V.A. Kostyuchenko, C. Xiao, M.C. Morais, C.D.S. Nelson, V.D. Bowman, A.J. Battisti, P.R. Chipman, C.R. Parrish, M.G. Rossmann, Asymmetric binding of transferrin receptor to parvovirus capsids, Proc. Natl. Acad. Sci. U. S. A. 104 (2007) 6585-6589, http://dx.doi.org/10.1073/ pnas.0701574104.

[67] E. Ablinger, S. Leitgeb, A. Zimmer, Differential scanning fluorescence approach using a fluorescent molecular rotor to detect thermostability of proteins in surfactant-containing formulations, Int. J. Pharm. 441 (2013) 255-260, http://dx.doi. org/10.1016/j.ijpharm.2012.11.035.

[68] Z Zhang, B. Greene, P.A. Thuman-Commike, J. Jakana, P.E. Prevelige, J. King, W. Chiu, Visualization of the maturation transition in bacteriophage P22 by electron cryomicroscopy, J. Mol. Biol. 297 (2000) 615-626, http://dx.doi.org/10. 1006/jmbi.2000.3601.

[69] R. Zandi, D. Reguera, Mechanical properties of viral capsids, Phys. Rev. E Stat. Nonlinear Soft Matter Phys. 72 (2005), http://dx.doi.org/10.1103/PhysRevE.72 021917.

[70] A. Ortega-Esteban, A.J. Pérez-Berná, R. Menéndez-Conejero, S.J. Flint, C.S. Martín, P.J. de Pablo, Monitoring dynamics of human adenovirus disassembly induced by mechanical fatigue, 3 (2013) 1434, http://dx.doi.org/10.1038/srep01434.

[71] M.A. Canady, M. Tihova, T.N. Hanzlik, J.E. Johnson, M. Yeager, Large conformational changes in the maturation of a simple RNA virus, nudaurelia capensis omega virus (NomegaV), J. Mol. Biol. 299 (2000) 573-584, http://dx.doi.org/10.1006/ jmbi.2000.3723.

[72] J.A. Speir, S. Munshi, G. Wang, T.S. Baker, J.E. Johnson, Structures of the native and swollen forms of cowpea chlorotic mottle virus determined by X-ray crystal. lography and cryo-electron microscopy, Structure 3 (1995) 63-78.

[73] G. RF, P. CN, Urea and guanidine hydrochloride denaturation curves, J. Biol. Chem. 249 (1974) 5388-5393, httt://dx.doi.org/10.1385/0-89603-301-5:177.

[74] C.N. Pace, K.E. Vanderburg, Determining globular protein stability: guanidine hydrochloride denaturation of myoglobin, Biochemistry 18 (1979) 288-292, http:// dx.doi.org/10.1021/bi00569a008.

[75] O.D. Monera, C.M. Kay, R.S. Hodges, Protein denaturation with guanidine hydrochloride or urea provides a different estimate of stability depending on the contributions of electrostatic interactions, Protein Sci. 3 (1994) 1984-1991, http://dx. doi.org/10.1002/pro.5560031110.

[76] J.L. England, G. Haran, Role of solvation effects in protein denaturation: from thermodynamics to single molecules and back, Annu. Rev. Phys. Chem. 62 (2011) 257-277, http://dx.doi.org/10.1146/annurev-physchem-032210-103531.

[77] M. Hernando-Perez, E. Pascual, M. Aznar, A. Ionel, J.R. Caston, A. Luque, J.L. Carrascosa, D. Reguera, P.J. de Pablo, The interplay between mechanics and stability of viral cages, Nano 6 (2014) 2702-2709, http://dx.doi.org/10.1039/ C3NR05763A.

[78] N.J. Greenfield, Using circular dichroism spectra to estimate protein secondary structure, Nat. Protoc. 1 (2006) 2876-2890, http://dx.doi.org/10.1038/nprot. 2006.202.

[79] B. Ranjbar, P. Gill, Circular dichroism techniques: biomolecular and nanostructural analyses- a review, Chem. Biol. Drug Des. 74 (2009) 101-120, http://dx.doi.org/ $10.1111 / \mathrm{j} .1747-0285.2009 .00847 . x$.

[80] S.M. Kelly, T.J. Jess, N.C. Price, How to study proteins by circular dichroism, Biochim. Biophys. Acta 1751 (2005) 119-139, http://dx.doi.org/10.1016/j. bbapap.2005.06.005.

[82] A. Llauro, D. Luque, E Edwards, B.L. Trus, J. Avera, D. Reguera, T. Douglas, P.J. de Pablo, J.R. Caston, Cargo-shell and cargo-cargo couplings govern the mechanics of artificially loaded virus-derived cages, Nano 8 (2016) 9328-9336, http://dx.doi. org/10.1039/C6NR01007E.

[83] A. Lazarus, H.C.B. Florijn, P.M. Reis, Geometry-induced rigidity in nonspherical pressurized elastic shells, Phys. Rev. Lett. 109 (2012) 1-5, http://dx.doi.org/10. 1103/PhysRevLett.109.144301.

[84] Y. Bai, J.S. Milne, L. Mayne, S.W. Englander, Primary structure effects on peptide group hydrogen exchange, Proteins 17 (1993) 75-86, http://dx.doi.org/10.1002/ prot. 340170110.

[85] L.S. Busenlehner, R.N. Armstrong, Insights into enzyme structure and dynamics elucidated by amide H/D exchange mass spectrometry, Arch. Biochem. Biophys. 
433 (2005) 34-46, http://dx.doi.org/10.1016/j.abb.2004.09.002.

[86] D. Balasubramaniam, E.A. Komives, Hydrogen-exchange mass spectrometry for the study of intrinsic disorder in proteins, Biochim. Biophys. Acta, Proteins Proteomics 1834 (2013) 1202-1209, http://dx.doi.org/10.1016/j.bbapap.2012.10.009.

[87] V.S. Reddy, P. Natarajan, B. Okerberg, K. Li, K.V. Damodaran, R.T. Morton, C.L. Brooks, J.E. Johnson, Virus particle explorer (VIPER), a website for virus capsid structures and their computational analyses, J. Virol. 75 (2001) 11943-11947, http://dx.doi.org/10.1128/JVI.75.24.11943-11947.2001.

[88] R.P. Bahadur, F. Rodier, J. Janin, A dissection of the protein-protein interfaces in icosahedral virus capsids, J. Mol. Biol. 367 (2007) 574-590, http://dx.doi.org/10. 1016/j.jmb.2006.12.054.

[89] V.S. Reddy, H.A. Giesing, R.T. Morton, A. Kumar, C.B. Post, C.L. Brooks, J.E Johnson, Energetics of quasiequivalence: computational analysis of proteinprotein interactions in icosahedral viruses, Biophys. J. 74 (1998) 546-558, http:// dx.doi.org/10.1016/S0006-3495(98)77813-0.

[90] M. Carrillo-Tripp, C.M. Shepherd, I.A. Borelli, S. Venkataraman, G. Lander, P. Natarajan, J.E. Johnson, C.L. Brooks, V.S. Reddy, VIPERdb2: an enhanced and web API enabled relational database for structural virology, Nucleic Acids Res. 37 (2009) D436-42, htt:://dx.doi.org/10.1093/nar/gkn840.

[91] J. Snijder, V.S. Reddy, E.R. May, W.H. Roos, G.R. Nemerow, G.J.L. Wuite, Integrin and Defensin modulate the mechanical properties of adenovirus, J. Virol. 87 (2013) 2756-2766, http://dx.doi.org/10.1128/JVL.02516-12.

[92] C. Carrasco, M. Castellanos, P.J. de Pablo, M.G. Mateu, Manipulation of the mechanical properties of a virus by protein engineering, Proc. Natl. Acad. Sci. U. S. A. 105 (2008) 4150-4155, http://dx.doi.org/10.1073/pnas.0708017105.

[93] S. Kang, P.E. Prevelige, Domain study of bacteriophage p22 coat protein and characterization of the capsid lattice transformation by hydrogen/deuterium exchange, J. Mol. Biol. 347 (2005) 935-948, http://dx.doi.org/10.1016/j.jmb.2005. 02.021 .

[94] R. Tuma, H. Tsuruta, J.M. Benevides, E. Prevelige Peter, G.J. Thomas, Characterization of subunit structural changes accompanying assembly of the bacteriophage P22 Procapsid, Biochemistry 40 (2001) 665-674, http://dx.doi.org/ 10.1021/bi001965y. 